\title{
أفق الخطاب النقدي ومنطلقاته المعرفية والفكرية والفلسفية \\ في مشروع إقبال الحضاري
}

$*$ عاشور مزيلخ

$$
\begin{aligned}
& \text { الملخص } \\
& \text { تدرس هذه الورقة المنطلقات المعرفية والفكرية والفلسفية لخطاب محمد إقبال في مشروعه الحضاري، المتميـز }
\end{aligned}
$$

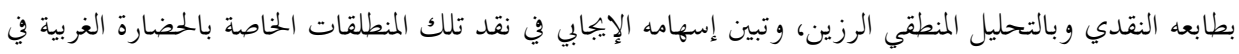

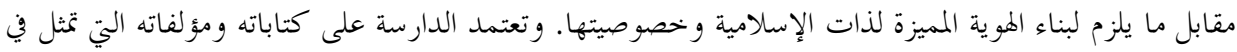

$$
\begin{aligned}
& \text { بحموعها مشروعاً نقدياً لبناء الشخصية الإسلامية المعاصرة. } \\
& \text { وأظهرت هذه الدراسة تميز خطاب إقبال النقدي بطابع خاص هدفه ترقية الختمع روحياً، والالتز ام بالتربيــة }
\end{aligned}
$$

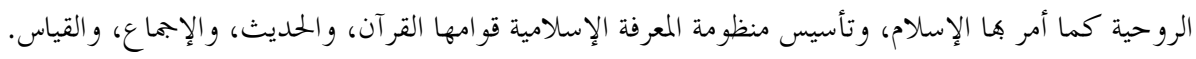

$$
\begin{aligned}
& \text { الكلمات المفتاحية: أفق الخطاب، المنهج النقدي، المنطلقات الفلسفية، المنطلقات الفكرية، المنطلقات المعرفية، }
\end{aligned}
$$

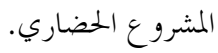

\section{Critical Discourse Horizon of Iqbal Cultural Project and its epistemological, Intellectual and Philosophical Premises}

\begin{abstract}
This paper examines the epistemological, intellectual and philosophical premises of critical discourse of Iqbal cultural project which is distinguished by its outstanding critical nature and sober logical analysis. The paper delineates the positive contribution of his criticism premises of Western civilization, and what it takes to construct a distinctive Islamic self- identity.

This study shows that Iqbal critical discourse is characterized by for spiritual nature to uplif the Muslim Society, develop commitment to spiritual education as ordained by Islam, and build Islamic knowledge system based on Holy Quran, Prophetic Hadith, consensus- Ijma' and deductive analogy- qiyas.

Keywords:, Discourse horizon, criticism approach, philosophical premises, intellectual premises, Epistemological premises, Civilizational project.

$$
\begin{aligned}
& \text { * دكتوراه في اللغة من جامعة الجزائر سنة ـ ا ـ بم، نائب رئيس قسم العقائد والأديان بكلية العلــوم الإســلامية } \\
& \text { جامعة الجزائر ا. البريد الإلكتروني: mezilak@gmail.com }
\end{aligned}
$$

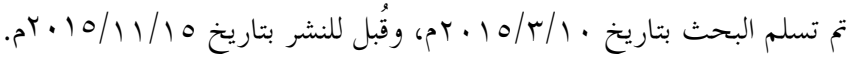




\section{مقدمة:}

سأحاول في هذا الدر اسة أن أقدم افتراضاً يقوم على تشييد ما سميته أفق الخططـاب

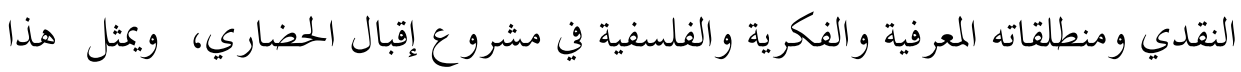

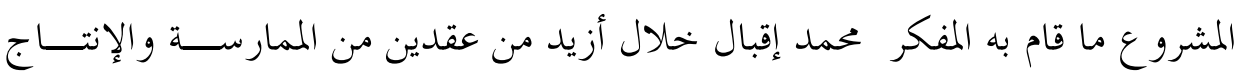

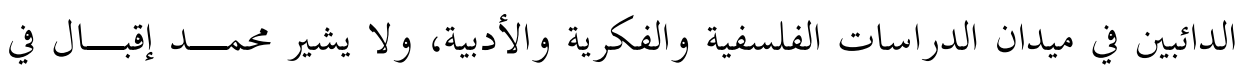

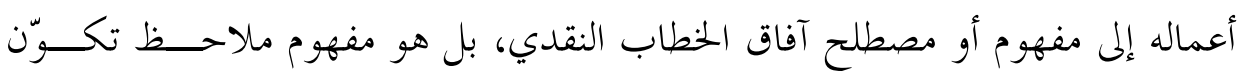
لدي أثناء قراءتي و تتبعي لمسار أعماله.

و.بما أن الأفق هو ما نرمي الوصول إليه، من تخطيط أو دراسة معززة بإمكانيــات

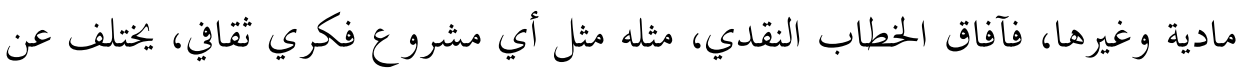

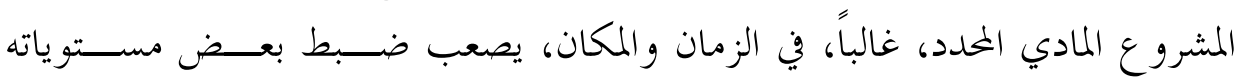

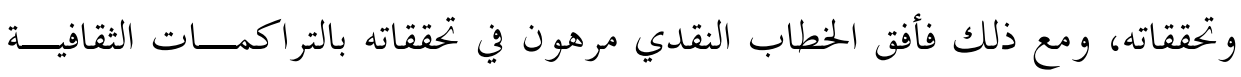
و الفكرية التي تخلقها قراءات وإبحاز ات متعددة للأفر اد.

وهذا البحث يترجم المنطلقات المعرفية والفكرية و الفلسفية للخطاب النقـــدي في

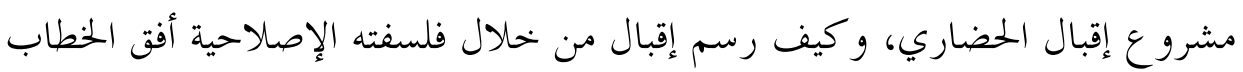

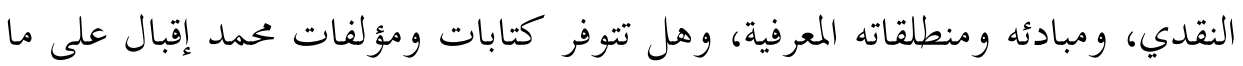

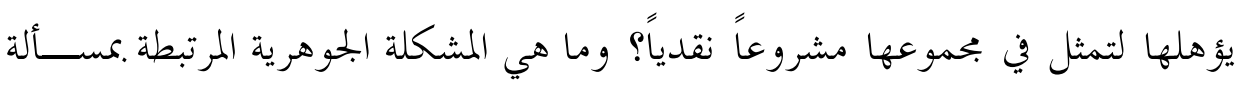

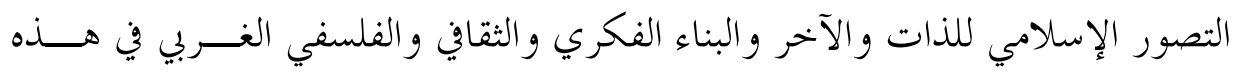

المقارنة؟

و نظراً لهذا كله أضحى من اللازم في زماننا دراسة أفق الخطاب النقدي ومنطلقاته

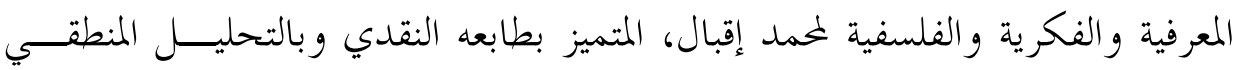

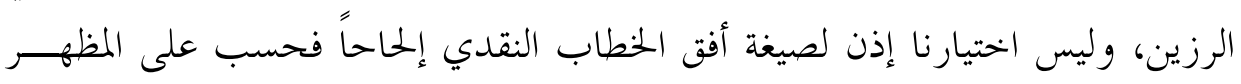

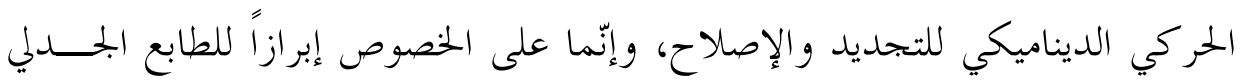

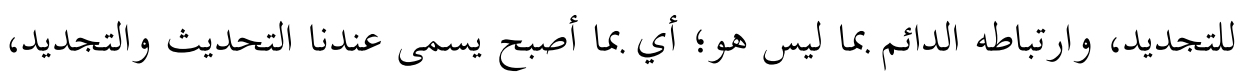


أفق الخطاب النقدي ومنطلقاته المعرفية والفكرية والفلسفية في مشروع إقبال الحضاري $\quad 79$

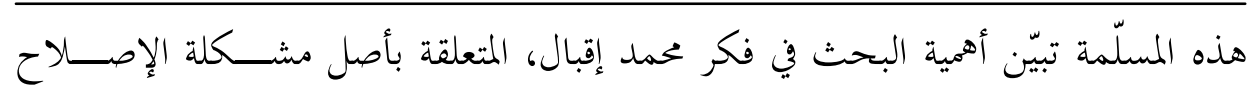

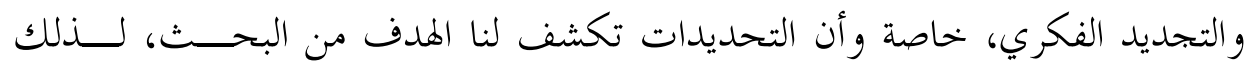
نحاول من خلال هذه الدراسة الوصول إلى الإجابة عن التساؤلات، من خلال: أولاً: مشروعية وأساس الخطاب النقدي ومقاربة إقبال الخطاب الحامل للخطاب

الديني.

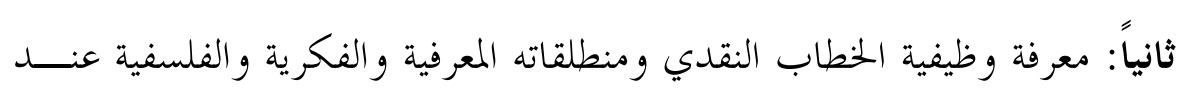

ثالثاً: هدف إقبال النقدي، مع بيان شروط الإبداع في الخطاب القرآني، وعلاقــة الجلديد و التجديد بالتراث.

رابعاً: معرفة أفق الخطاب النقدي وهدفه عند إقبال ودوره في بنــــاء الشخصــية الإسلامية المعاصرة.

و نظراً لخصوصية الموضوع الذي نتناوله في دراستنا و التي تمت بصلة مباشرة لعلمي

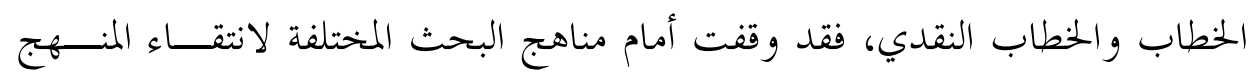

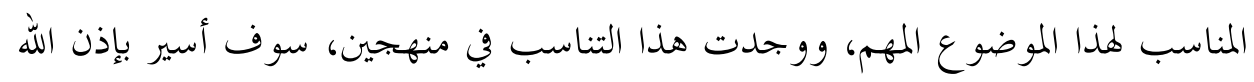
عليهما أثناء تلك الدراسة وهما: المنهج الاستقرائي الاستدلالي والمنهج التحليلي. وسوف أستعرض في البداية الخطاب النقدي: مبادئه ومنطلقاته، ثم أعرض هدف إقبال النقدي وعلاقته بنقد القراءة الحداثية والتراثية.

\section{أولاً: مبادئ الخطاب النقدي ومنطلقاته المعرفية و الفكرية والفلسفية عند إقبال}

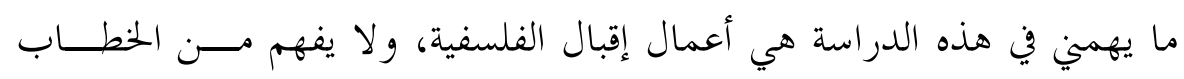

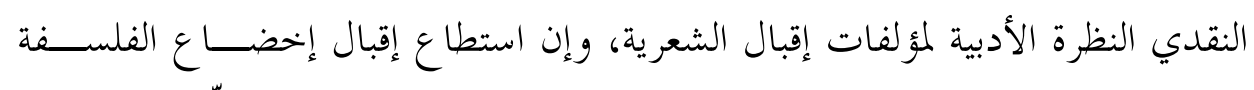

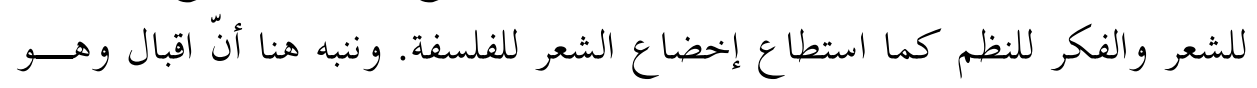

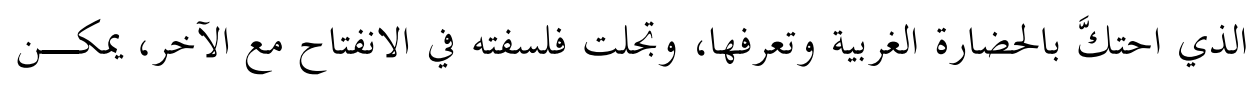




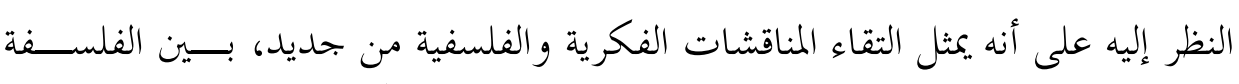

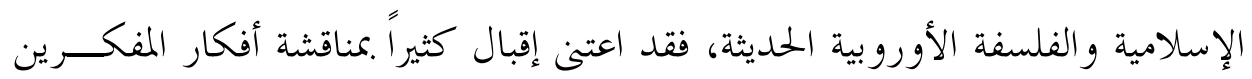

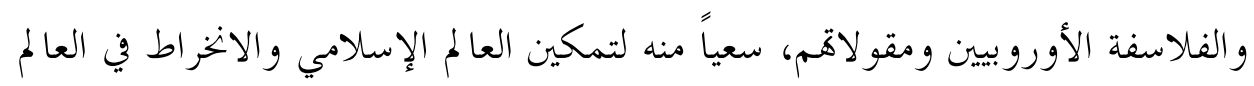

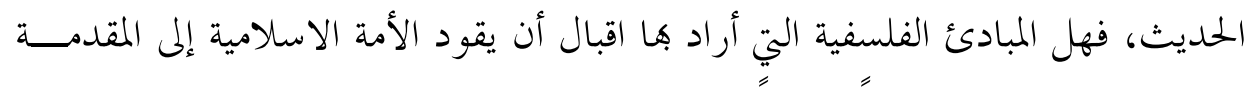
كفيلة ببناء فلسفة دينية بناءً جديدًا

\section{ا ـ مبادئ الخطاب النقدي عند إقبال:}

من خلال قراءتنا لأعمال إقبال وسعيه ضمن مشروعه النقدي المعبّر عنه في ثنايـــا

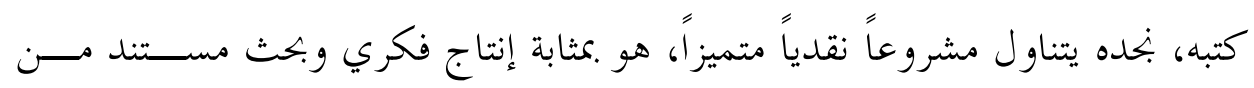
معطيات فلسفية، انطلاقاً لما يراه من الخمول و الكسل و اللامبالاة التي أصيبت هيا الأمة. وتقوم أعمال محمد إقبال على بحموعة من المبادئ التي تؤهلها؛ لتشكل مشروعاً نقدياً مبادئ ميزت تحليلات إقبال النقدية، ويمكن إيجازها فيما يأتي:

\section{أ. مبدأ مشروعية الخطاب النقدي المستمر والمنتظم:}

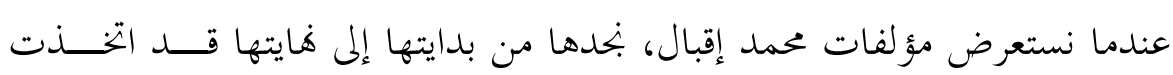
مساراً منتظماً، تكمن من خلالها مشروعية خطابه النقدي، في ما سعى إليه بإعادة بناء

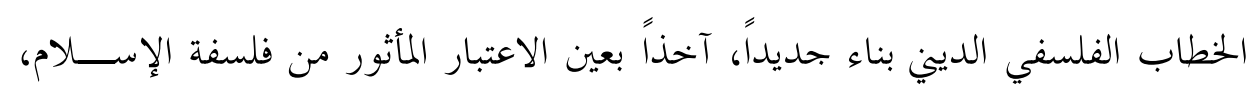
وذلك نتيجة تطور المعرفة الإنسانية، منتقداً ضعف تفكير المسلمين وانشغالهم بأنفسهم.

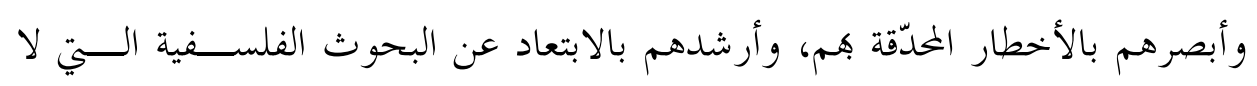

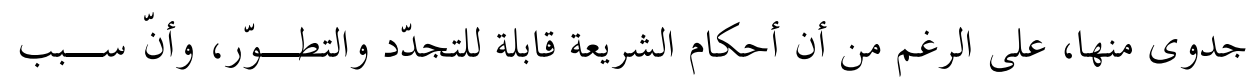

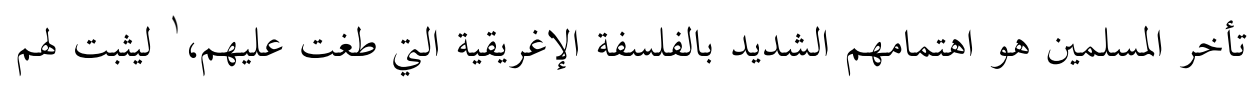
أنّ أوروبا هضت لما ثارت على هذه الفلسفة، واشتغلت بعلوم الطبيعة المنتجة، وبيجهد إقبال العظيم المتميز بند مؤلفاته قد ظهرت بالصورة الآتية:

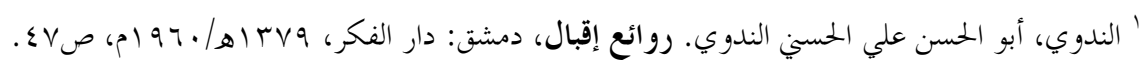


VI أفق الخطاب النقدي ومنطلقاته المعرفية والفكرية والفلسفية في مشروع إقبال الحضاري عاشور مزيلخ

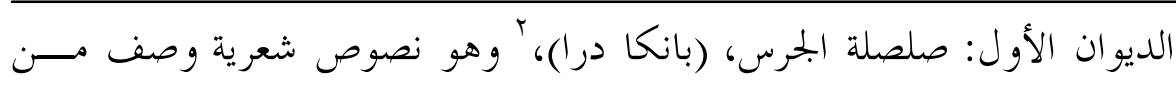

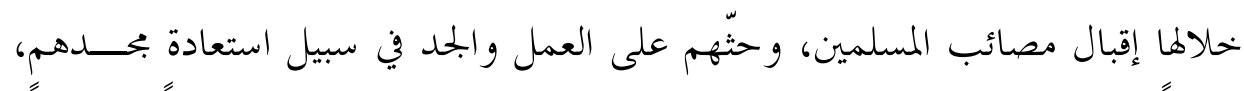

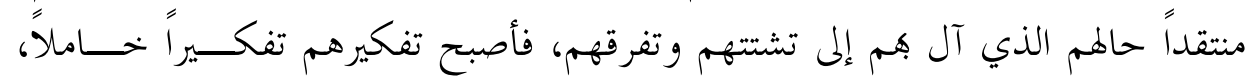

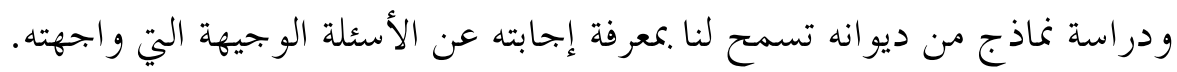

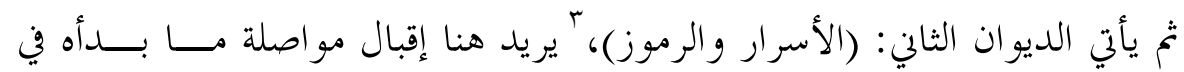

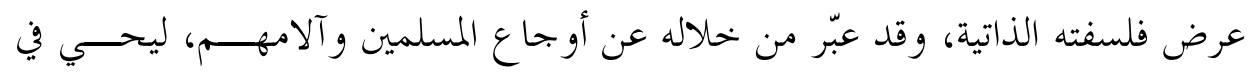

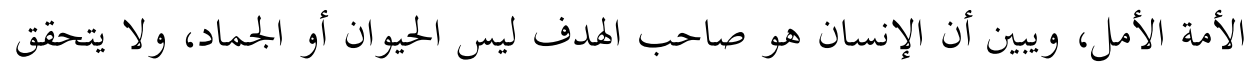
ذلك إلا بالعلم. - 20 - ملك.

و في الديوان الثالث: رسالة الشرق، (بيام مشرق)، بند إقبال ينفتح في تطبيقاتــهـ

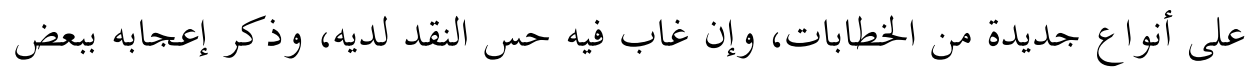

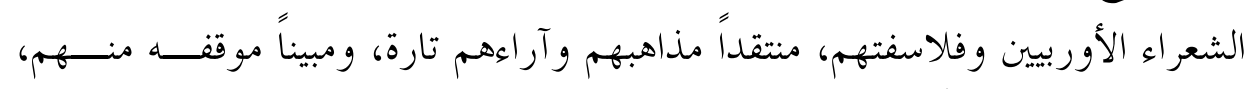

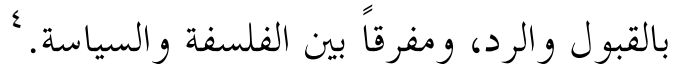

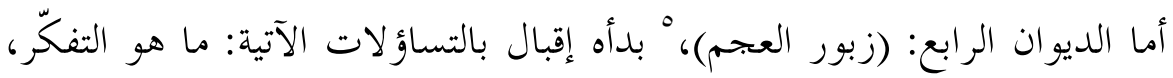

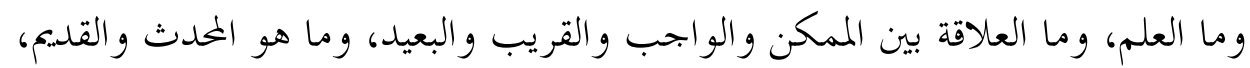

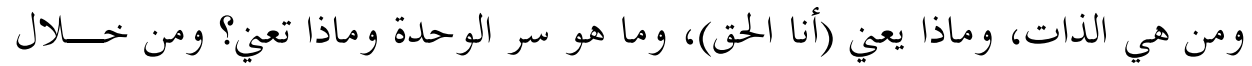

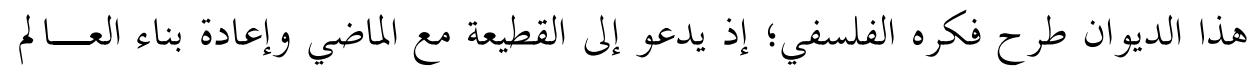
من جديد.

و يكون الديوان الخامس (بال جبريل)، جناح جبريل، ديو ان شعر لإقبال: .مثابــة

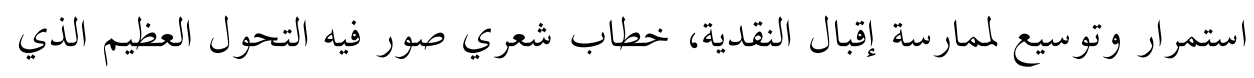

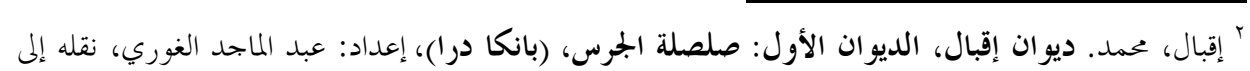

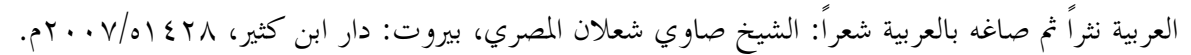

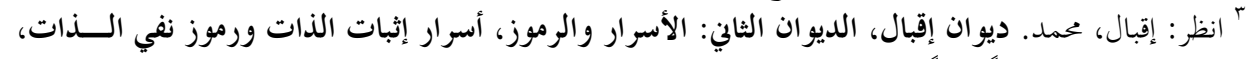

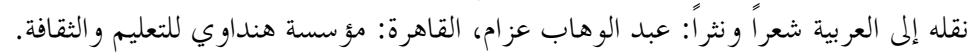

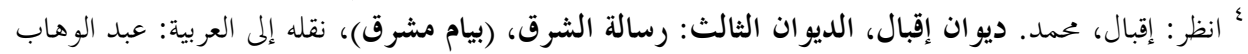

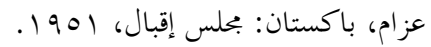
• انظر: إقبال، محمد. ديوان إقبان، إقبال، الديوان انوان الرابع: زبور العجم، نقله إلى العربية شعراً: حسين بحيب المصــري،

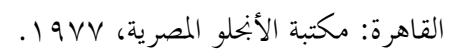


أصاب الأمة الإسلامية، نتيجته ضعف العالم الإسلامي في العاطفة والحب، فإذا بتحـــد

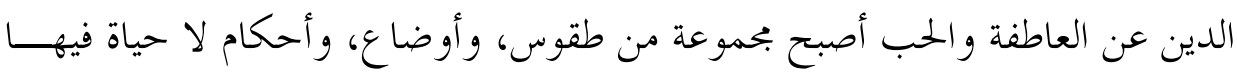
ولا روح، ولا حماسة فيها ولا قوة.

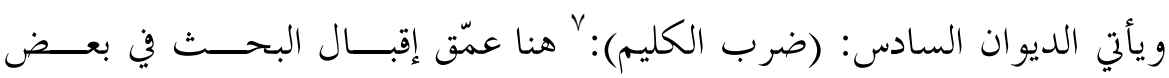

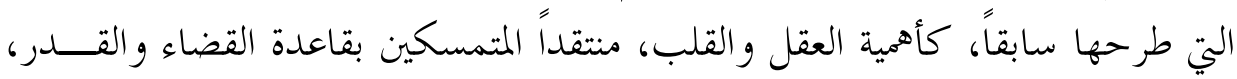
وأن سبب نوم الشعوب هو غياب الذات.

و يستعرض إقبال في الديوان التاسع هدية الحجاز، (أرمغان حجاز)، الابجاهـــات و المذاهب السياسية وزعماءها، في صورة جلسة برلمانية حضرها شياطين العالم وو كلاء

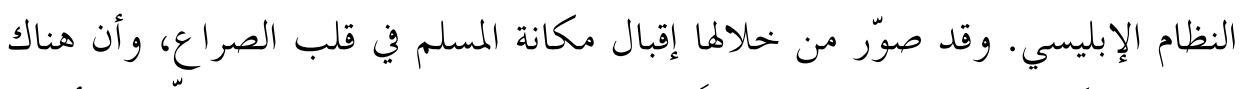

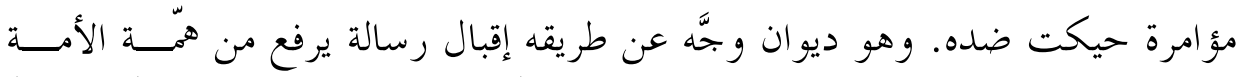

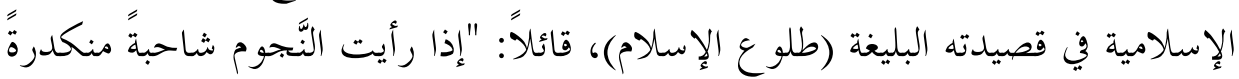

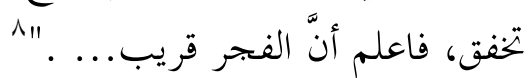

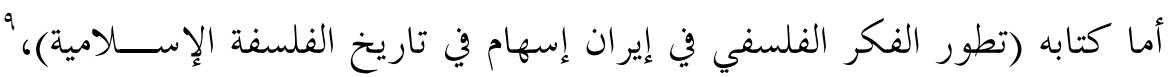

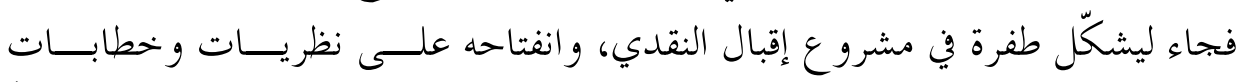

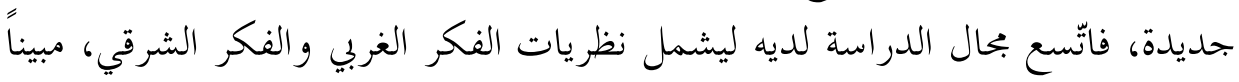

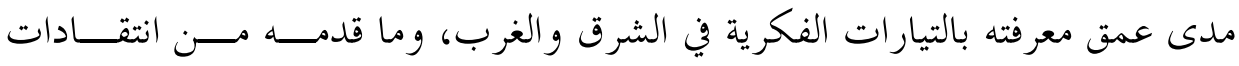

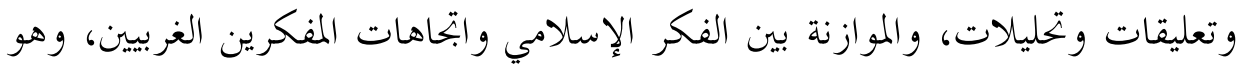
ما ميّز مشرو ع الخطاب النقدي لإقبال.

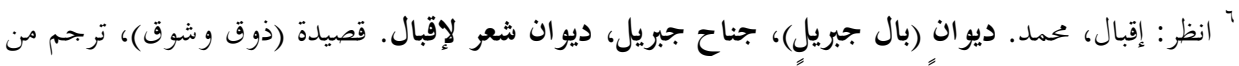

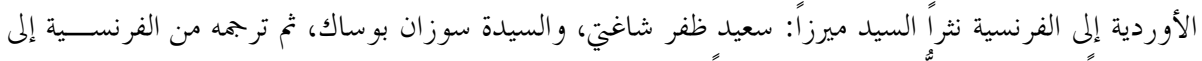

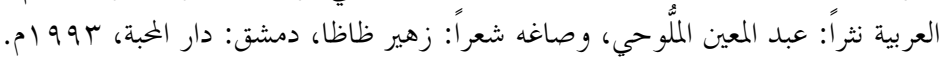

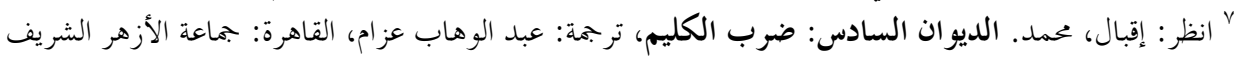

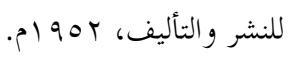

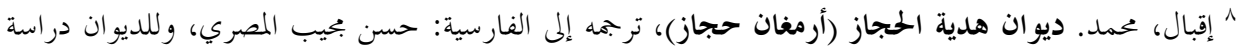

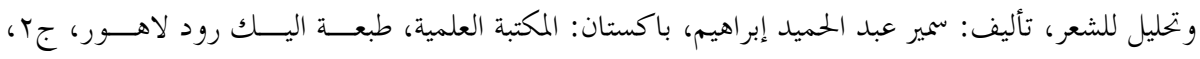
ص. 0.00

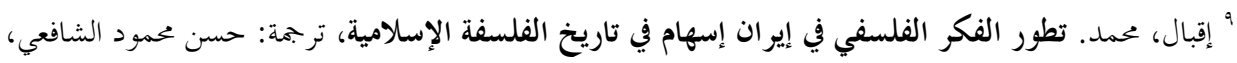

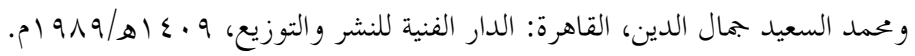




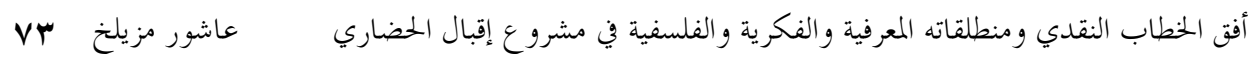

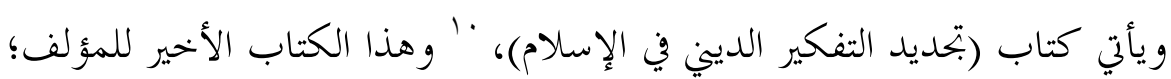

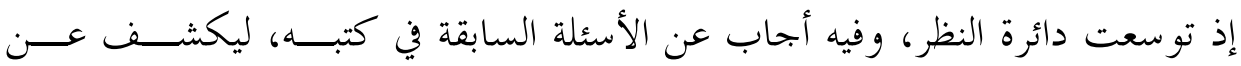
مشروعه الحضاري، إصلاح الفكر الإسلامي لإعادة بنائه من الداخل. و ونستطيع القول إنه خرج من صلب بتربته السابقة؛ إذ يدفع مشروعه النقدي ليوضح الغرض منه بن بيان

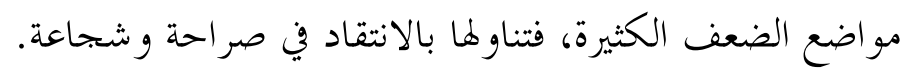
مؤلفات إقبال .مثثابة أفق جديد للدارسين، وإبحازات لإغناء الخططــاب الإســلامي نظرياً و مفهومياً ومنهجياً.

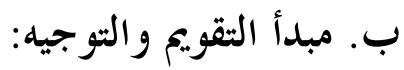

لا شكّ في أنّ عناوين محمد إقبال تفصح عن ثابت منهجي يقوم عليه مشـــروعه

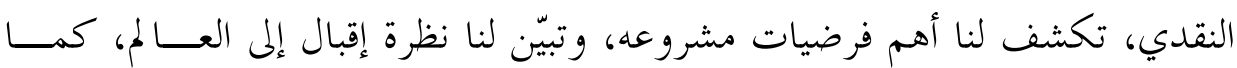

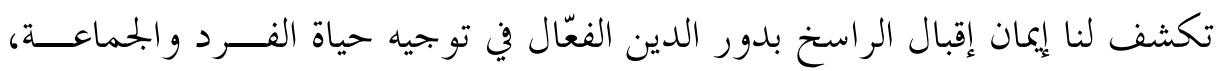

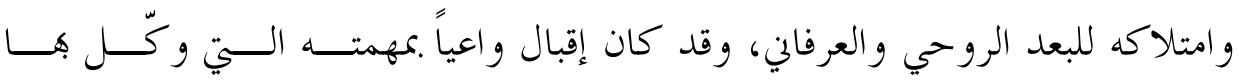

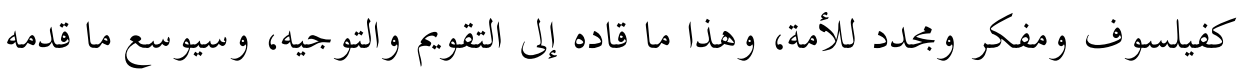
من خلال:

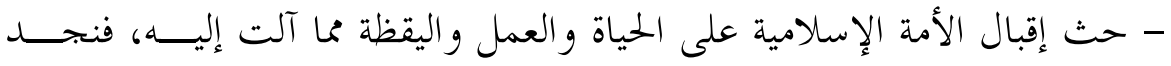

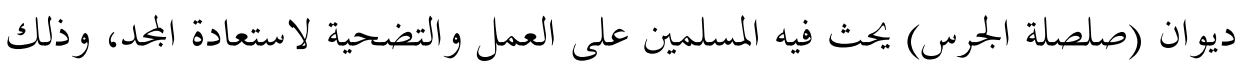
في قصيدة "الشكوى وجواب الشكوى"؛ لأنّ هدف الإنسان في تصور إقبال هو إثبات

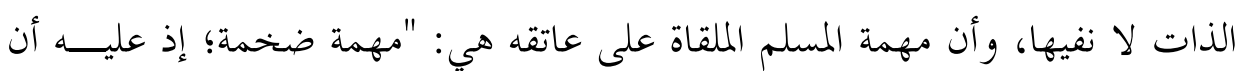

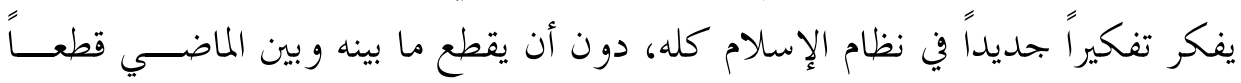

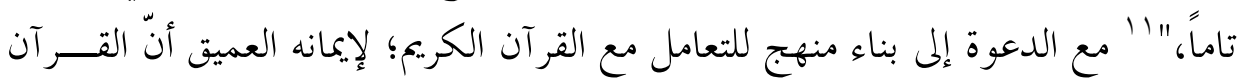

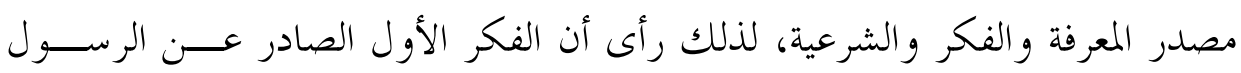
مقبول و كافٍ في تلك المرحلة من أمتنا. •' إقبال، محمد. تجديد التفكير الديني في الإسلام، ترجمة: عباس محمود، القاهرة: دار الهداية للطباعة والتوزيــع، . التوم.

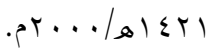

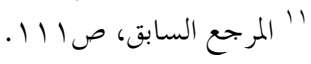




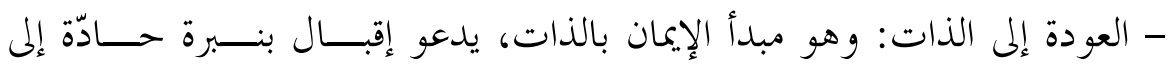

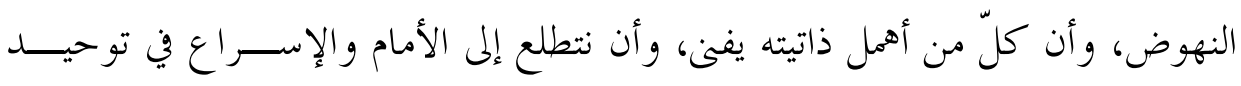

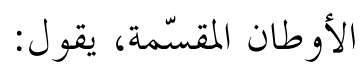

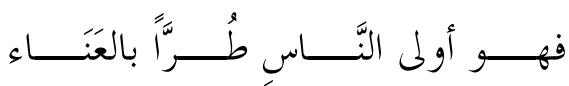

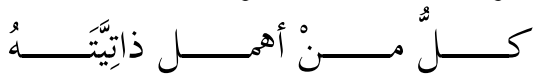

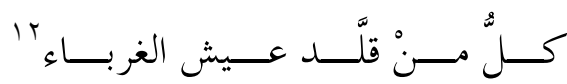

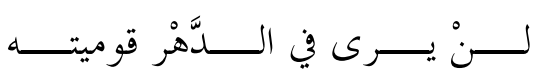

- حزن إقبال لأحو ال الأمة وأوضاع العرب الفاسدة، بسبب عبــث ملـــو كهم

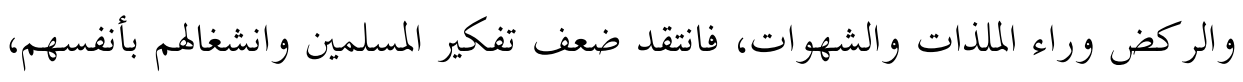

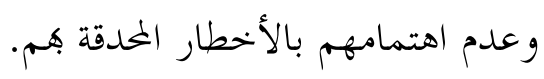

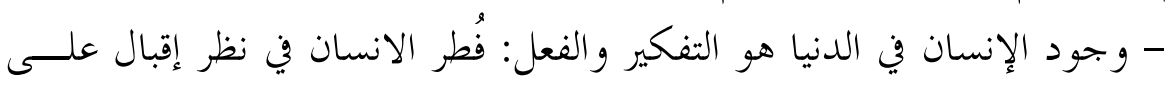

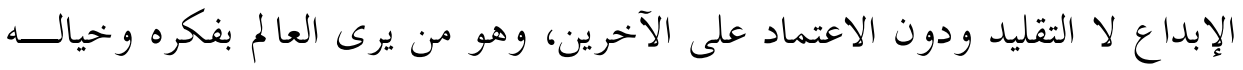

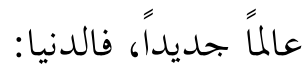

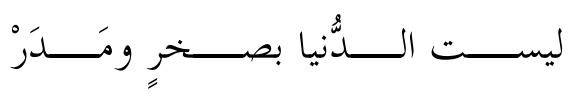

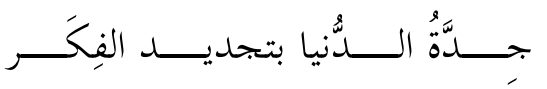

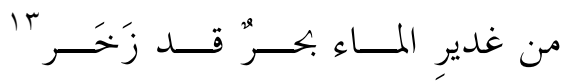

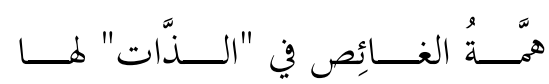

\section{ت. مبدأ ايمان إقبال بحرية الفكر والتأويل:}

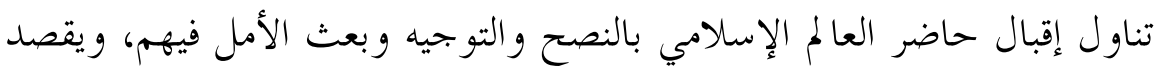

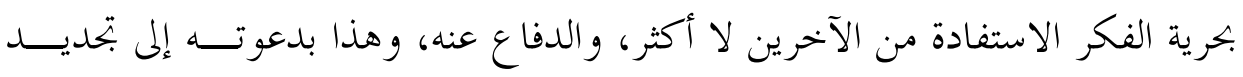

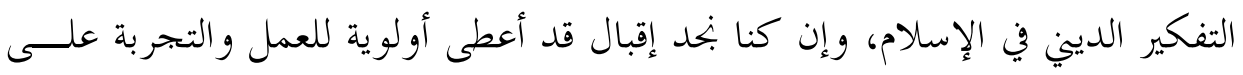

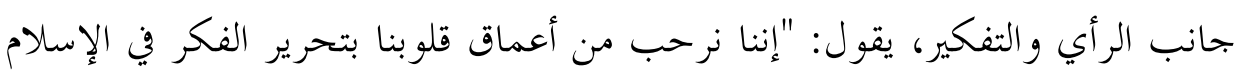

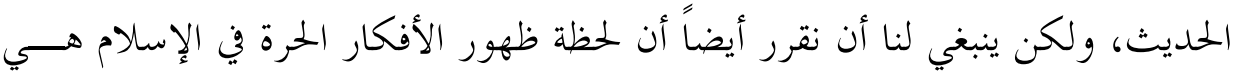

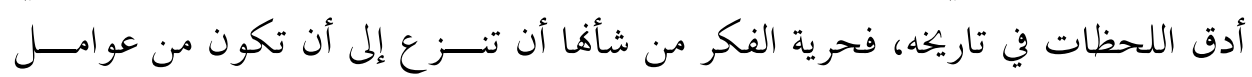

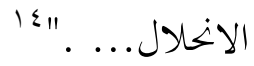

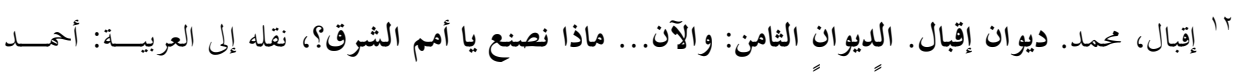

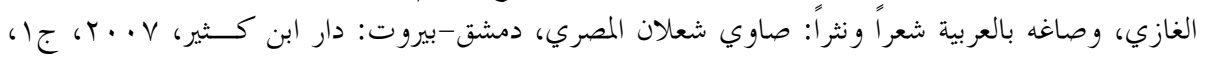

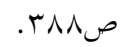

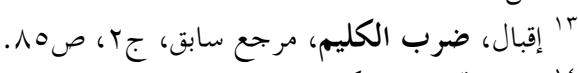

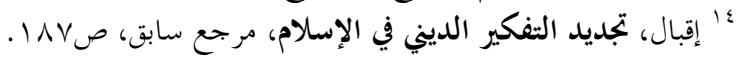


Vo عاشور مزيلخ أفق الخطاب النقدي ومنطلقاته المعرفية والفكرية والفلسفية في مشرو ع إقبال الحضاري

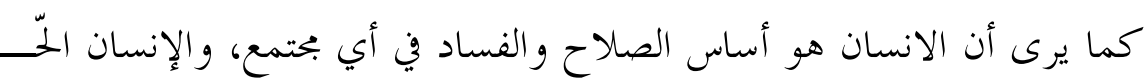

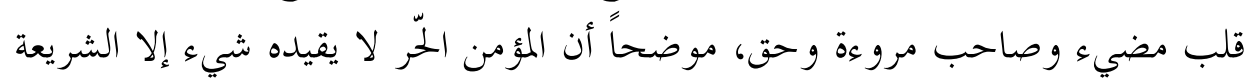

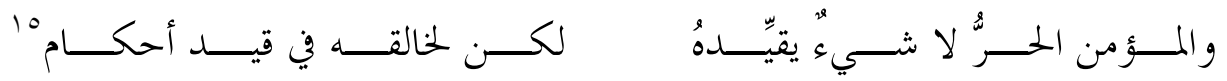

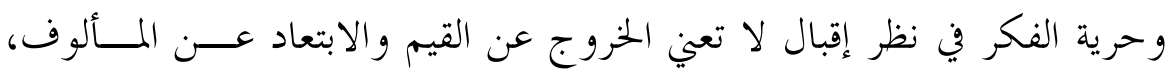

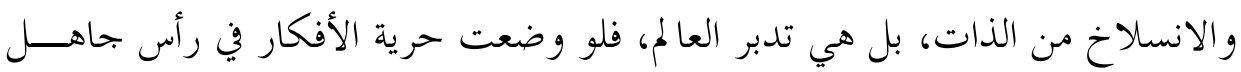
لجعل الناس هُائم. 17

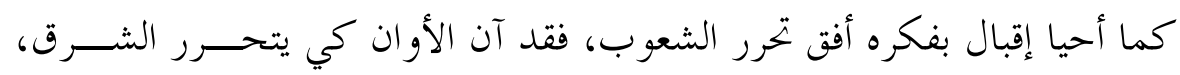
بالثورة على النفوس و كسر القيود، بعد هذا السبات الطويل، يقول:

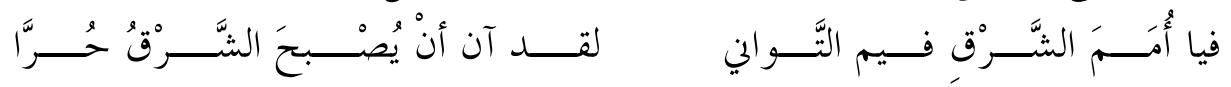

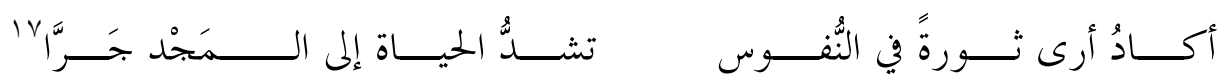

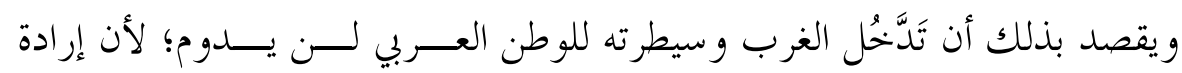
الشعوب أقوى من كلّ شيء، هدفه هو يقظة المسلمين كأمة وجماعة.

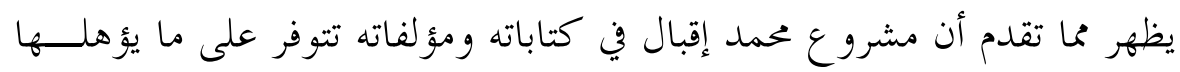

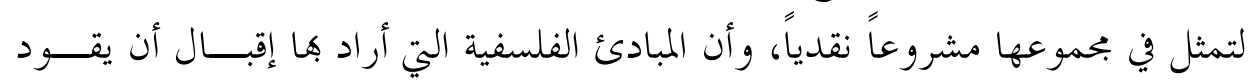

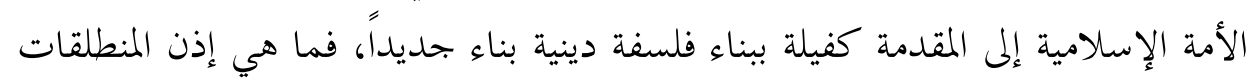

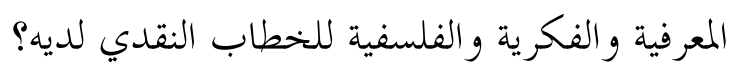

\section{Y r المنطلقات المعرفية والفكرية والفلسفية للخطاب النقدي عند إقبال:}

أكّد إقبال في العديد من مؤلفاته منطلقاته المعرفية والفكرية والفلسفية التي حفّزته

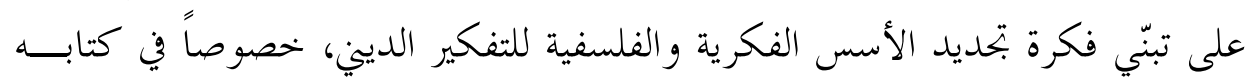

$$
\begin{aligned}
& \text { (بتديد التفكير الديني في الإسلام). }
\end{aligned}
$$

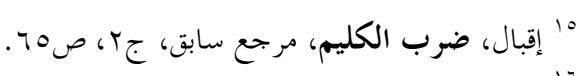

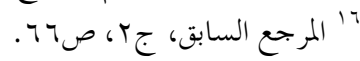

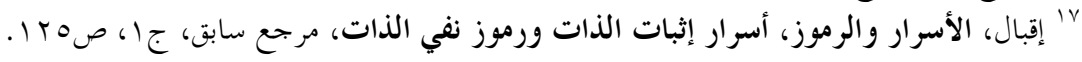


فهل كانت المنطلقات المعرفية و الفكرية و الفلسفية ذات بعد علمي، ضمن رؤيسـة يشكلها الفكر الديني الإسلامي، أو ذات مظاهر دينية إسلامية تقود الأمة الإسلامية إلى ولى

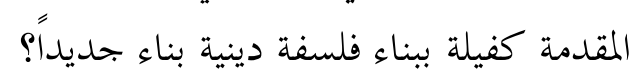

\section{أ. نشأته في بيت إسلامي واتصاله الدائم بالذات الإسلامية:}

نستطيع القول إن معرفة إقبال بالقرآن الكريم و السنة النبوبة المطهــــرة، والتـــاريخ

الإسلامي البحيد، و المعرفة بالحياة الإنسانية، من أهم المصادر الأساسية في فلسفة إقبــال

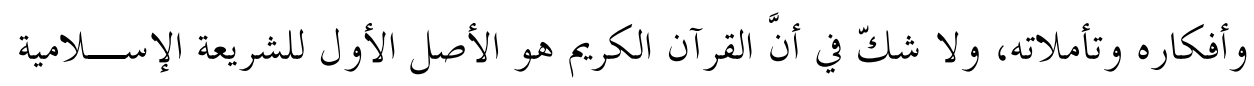

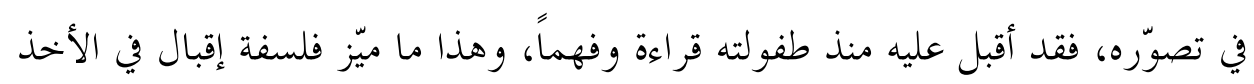

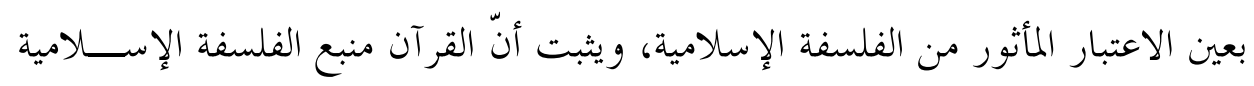
يعارض الفلسفة اليونانية في جوهرها، التي غشت أبصار بعض مفكري الإسلام في فهم القرآن، ^ا يريد بذلك أن يكون الفكر الديني شديد الصلة بالواقع.

كما أن شعر إقبال وإن كان باللغة الفارسية، فإن مضمونه نـــابع مـــن الـــروح

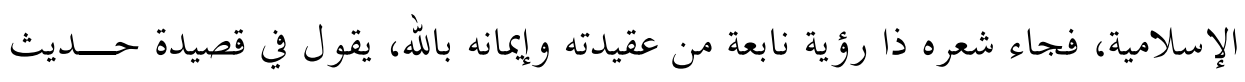

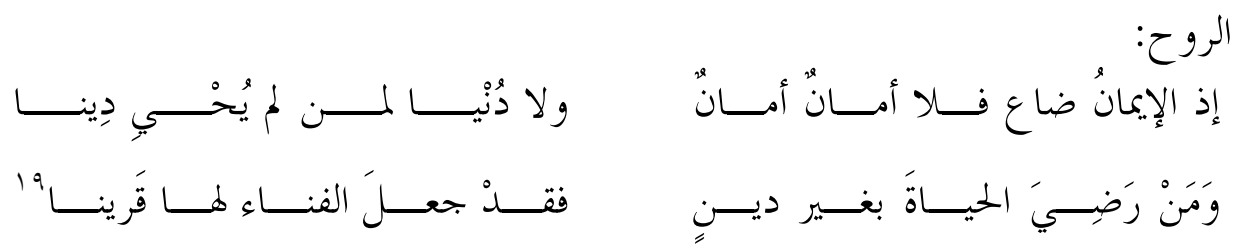

هنا تتضح رؤية إقبال المتميزة في الاستفادة من القرآن الكريم في ضـــوء حركـــة خطابه النقدي الإصلاحي التجديدي، وأنه منبع فلسفته، فهي كلها غايـــة الإســالام و مقصده.

وتحتل السيرة النبوية المباركة مكانة مهمة في كتابات إقبال، فهي المصدر الثـــاني،

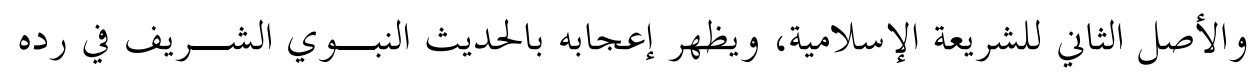




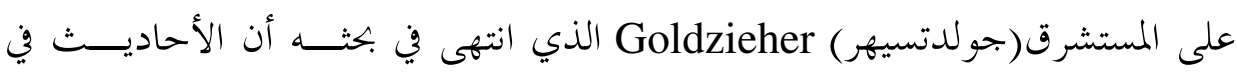

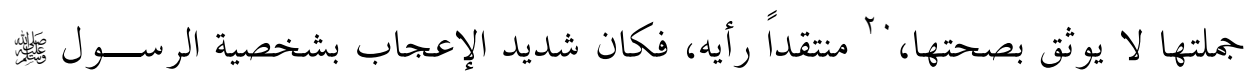

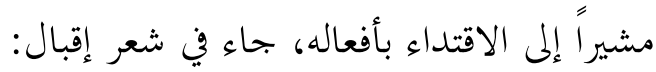

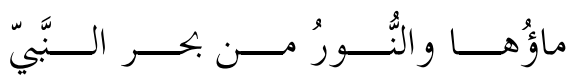

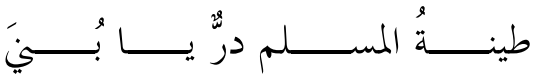

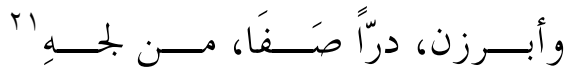

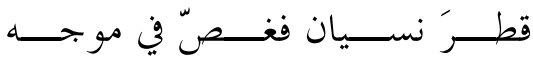

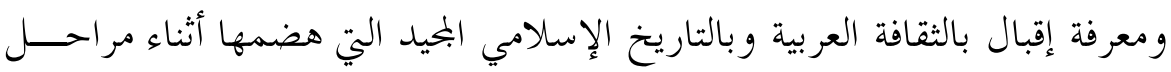

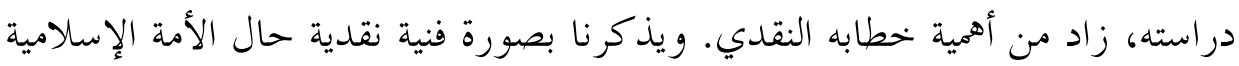

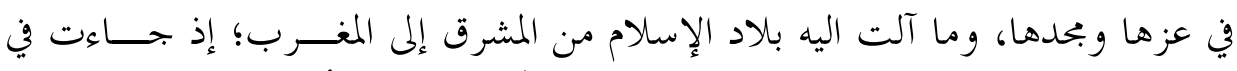

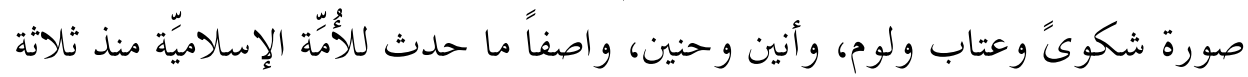

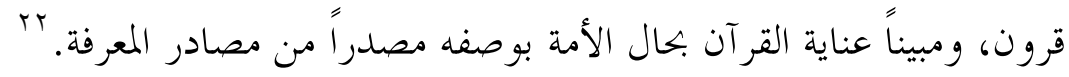

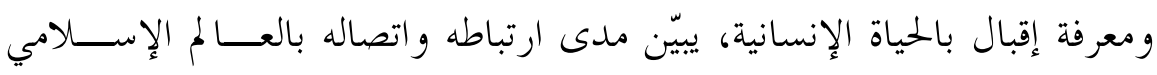

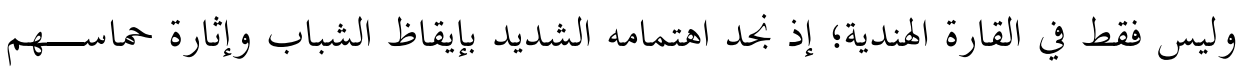

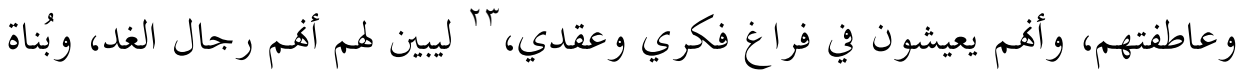

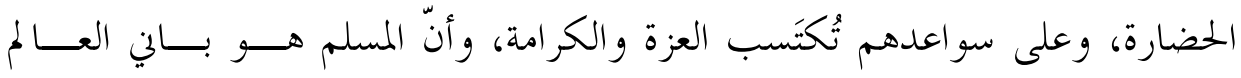

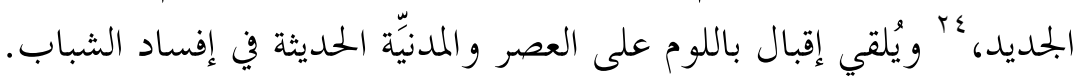

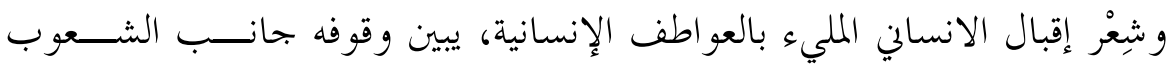

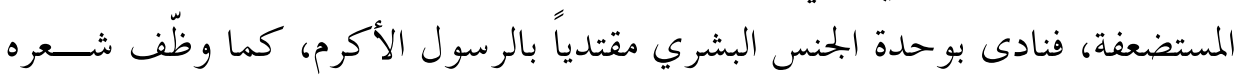

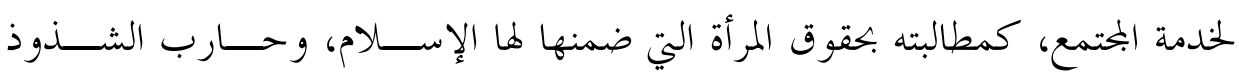
و الفساد و السفور.

يبحد المشروع النقدي لإقبال تحققاته في نموه المطّرد و تأثيراته الفعلية واهتمامه بكل

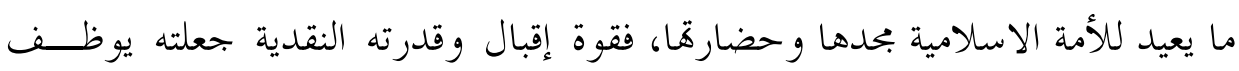

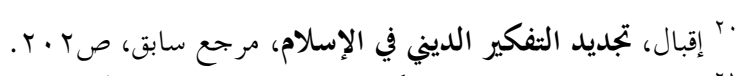

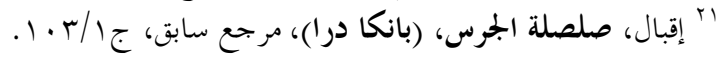

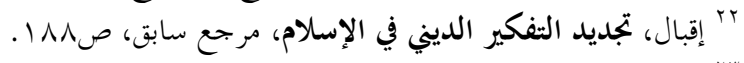

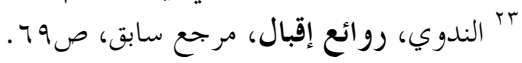

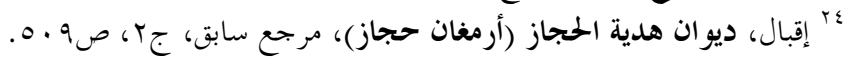


معرفته بالتاريخ الإسلامي، مما أثمر رؤية رسمت لنا فلسفته للحياة و الوجود والإنســان و التاريخ.

\section{ب. معرفة إقبال للثقافة الغربية أوسع من معرفته بالثقافة الإسلامية:}

يمتلك إقبال معرفة واسعة وعميقة بالأفكار الفلسفية والاجتماعية الغربية، لاتصاله المبكر بالفلسفة وتكوين المعرفة هـا، وتعمقه في دراستها وتحصيلها في جامعات غربيـــة

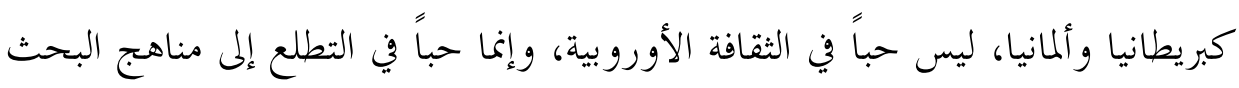

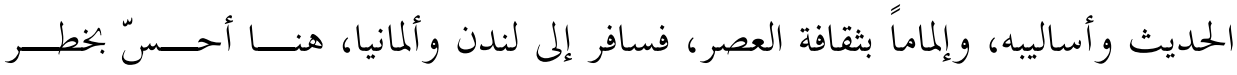
التيارات المنحرفة في أوروبا، وتطلع كثير من شباب المسلمين نخو الثقافة الغربية.

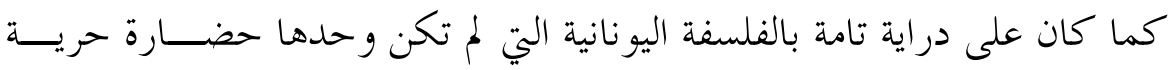
الفكر، فكثير ما وقع فيها اضطهاد المفكرين الأحرار مثل سقر اط وأفلاطون، مُ و كان

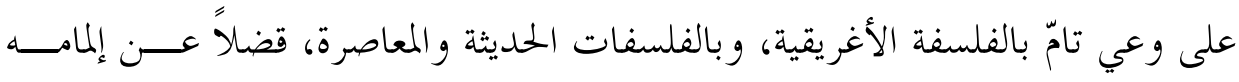

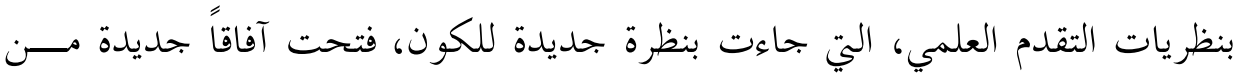

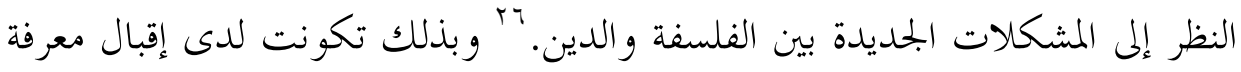

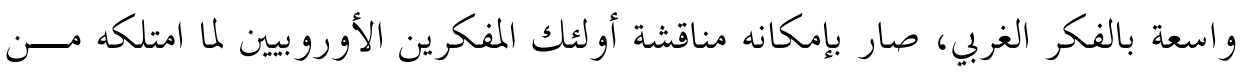
كفاءة وقدرة على ذلك.

ولعل هذا جعل إقبال يعتمد أكثر على الفكر الغربي في فهـــم المـــوروث العــــبي

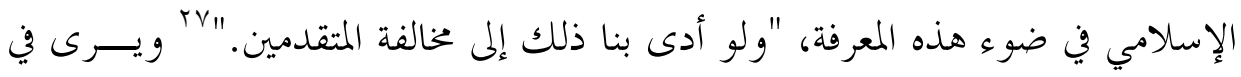

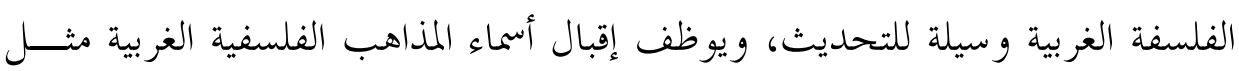

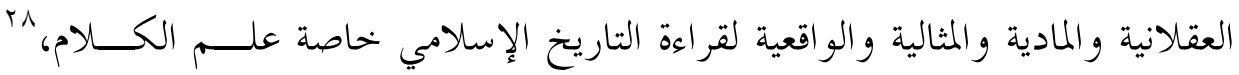

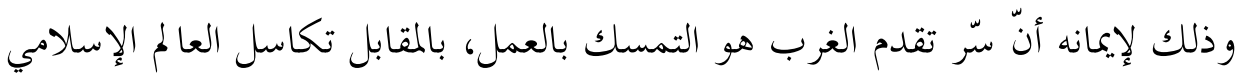

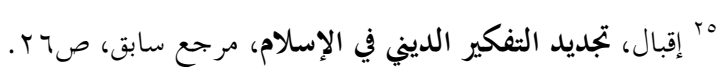

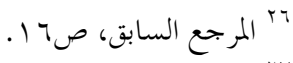

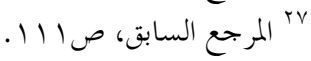

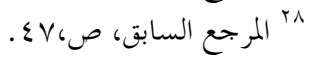




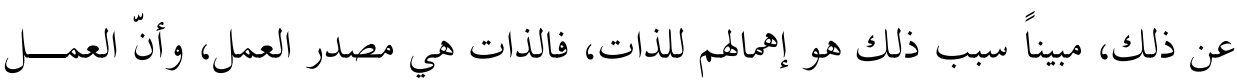

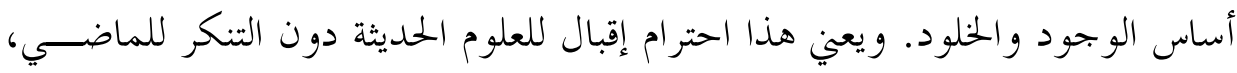

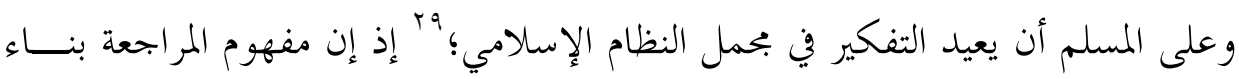
على تطور المعرفة جزء أساسي في تطور الفكر الإسالامي.

و وعرفة إقبال الواسعة للثقافة الغربية لا ينفي أنه صاحب ثقافة جامعة بين الثـــرق و الغرب، فانتهج سياسة الهدم والنقد، ووقف منها موقف الناقد الرافض، وغير المتقبل لظروف الجمتمع الغربي وحضارته وأفكاره، يذكر منتقداً الفكر العقلاني الغربي في قوله:

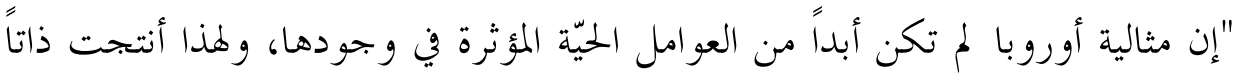

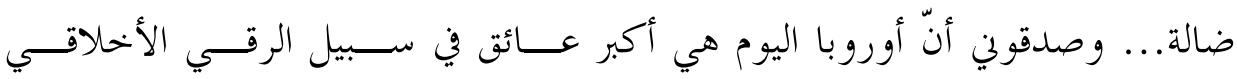

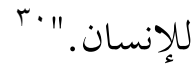

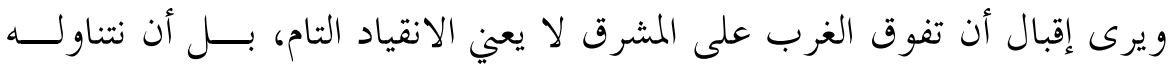

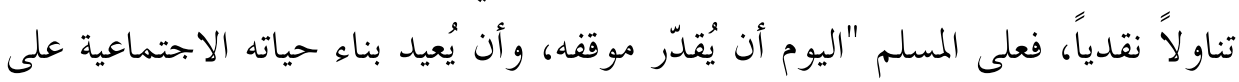

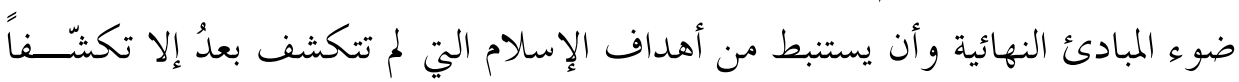

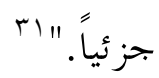

ولهذا فإن منطلقات إقبال المعرفية الواسعة و العميقة للأفكار الفلسفية والاجتماعية الغربية، تظهر المشروع النقدي لإقبال، وأنه لا يريد أن يحمل النقد على مناهج غربية،

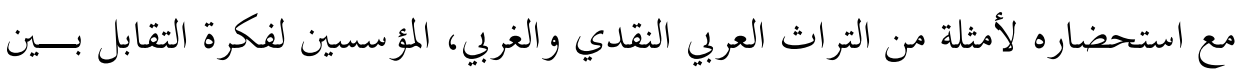
التراث العربي القديم و الثقافة الأورو بية الحديثة.

\section{ت. معالجة إقبال لقضايا المسلمين بأفكار فلسفية:}

يعرض إقبال أفكاره ووجهات نظره ثم يعالجها بأفكار فلسفية وفقاً لطبيعة المسألة

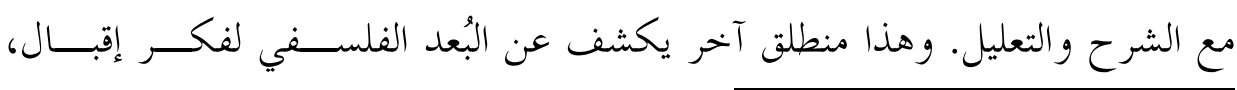




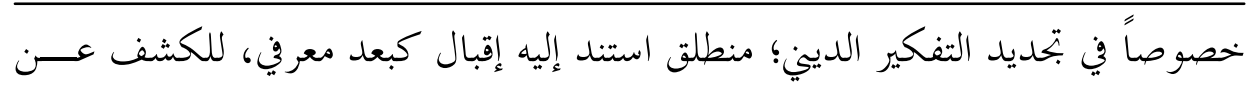

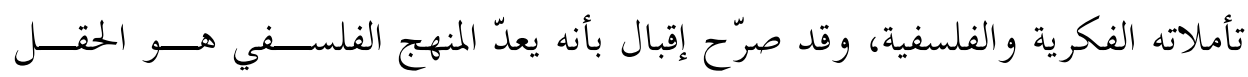

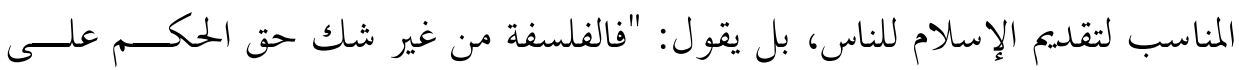

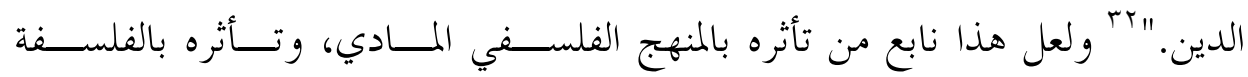

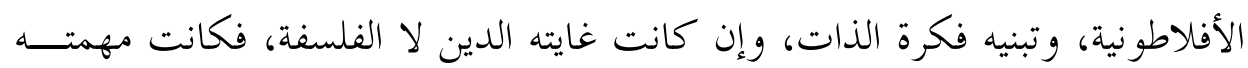

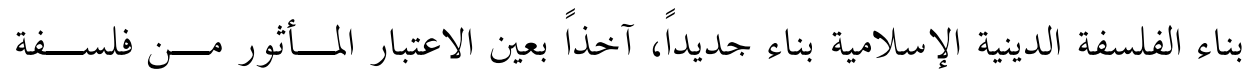

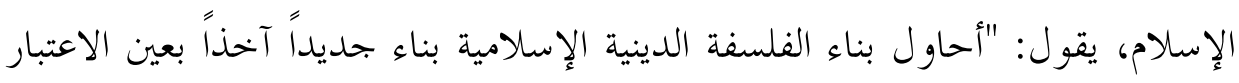

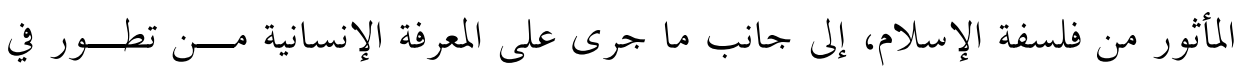

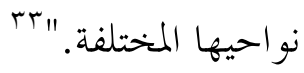

لذلك فالعناصر المنهجية التي يكتب هما إقبال ترتبط بأساس نظري وفلسفي، وإن

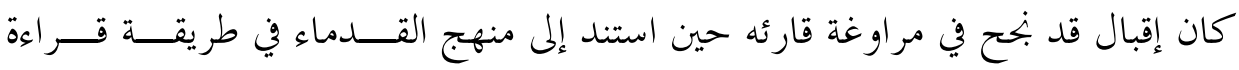

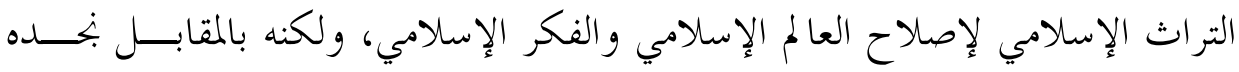

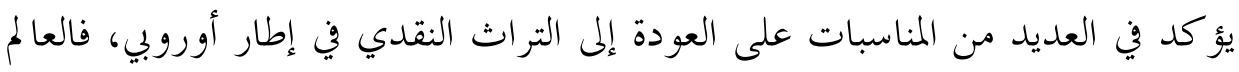

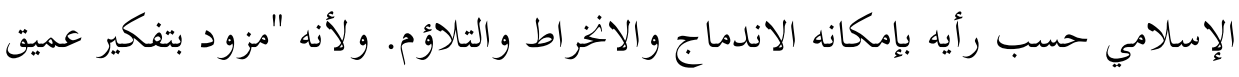

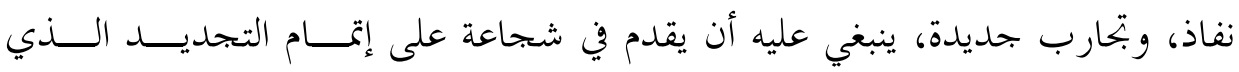

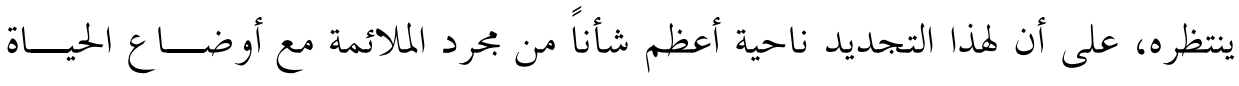

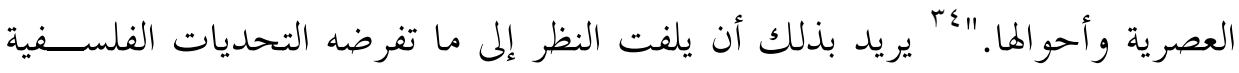
الفكرية و العلمية.

و تصور إقبال الذاتي وتقويمه لبعض الحركات الحلديثة الــتي ظهــرت في العـــالم الإسلامي كالبهائية و القاديانية و حركة كة أتاتورك في تركيا، ومعايشته تلـــك الأفكــــار

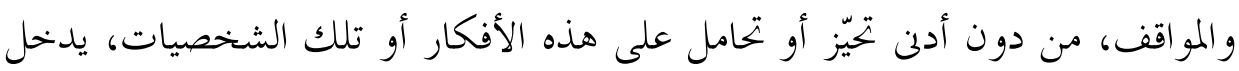
هذا ضمن دفاعه عن حرية الفكر و التأويل. ور.بما أراد إقبال لفت انت انتباه الشباب المسلم بعد أن تشبث بالغرب ونفى الذات، ليعود لحاضرة أمته ويشدّهُ إلى وطنه.

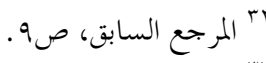

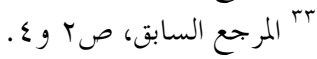

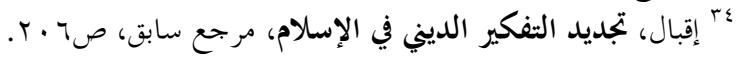


أفق الخطاب النقدي ومنطلقاته المعرفية والفكرية والفلسفية في مشروع إقبال الحضاري عاشور مزيلخ

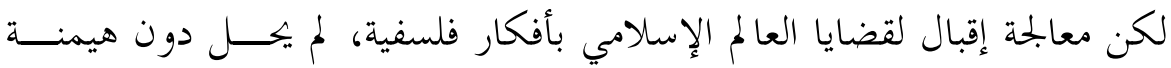

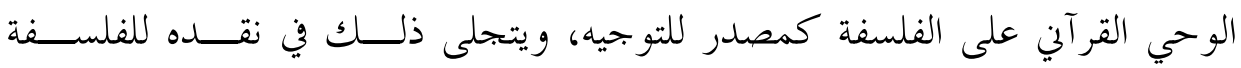

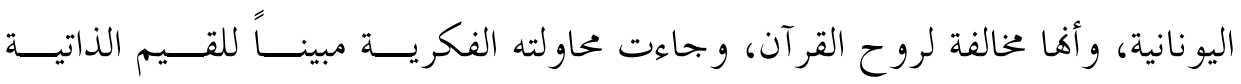
للإسلام، و منتقداً الفكر الفلسفي الإسلامي و ابتحاهاته الكبرى، عند الأشــــاعرة مــــلاً و المعتزلة وأبي حامد الغزالي وابن رشد وغيرهم، ومدى تأثرهم بالفلسفة اليونانية. و تبيّن أعمال إقبال الشعرية والنثرية مدى اهتمامه .موضو ع التصـــوف و الأفكـــار الصوفية في المحال الإسلامي، ببيان دور القدماء من الصوفية، منتقداً في ذات الوقـتـت

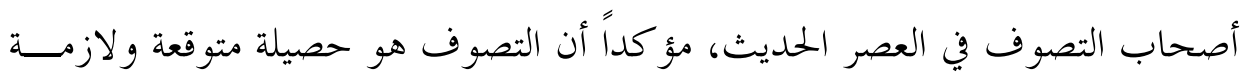
لما تمخضت عنه قوى فكرية و أخلاقية شتى، منتقداً آراء المستشرقين غــير الصــحيحة الذين ربطو ا نشأة التصوف في المجال الإسلامي .كؤثرات خارجية، مثل فون كريمــــــ

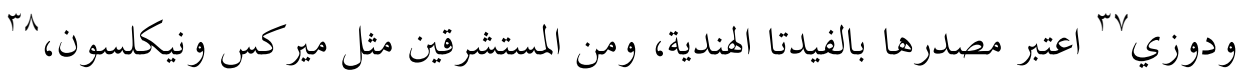
حدد مصدرها بالأفلاطو نية الحديثة.

كعنى أن فلسفة محمد إقبال الدينية الإصالاحية ما هي إلا استمرار لجلذوة التجديــــ للحضارة العربية الإسلامية، لأنّه أعاد قر اءة الفكر الإسلامي وفق تصـــور إنســـاني في

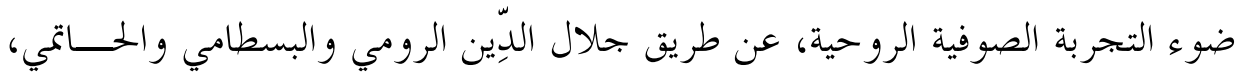
ro

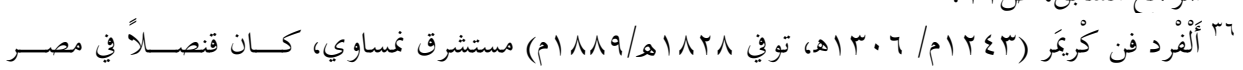

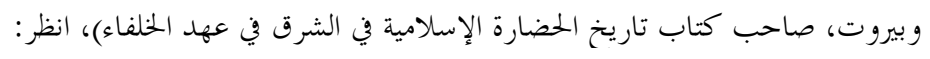

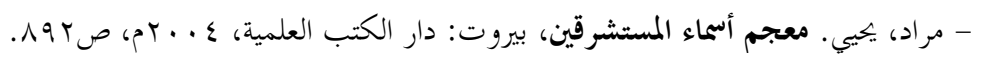

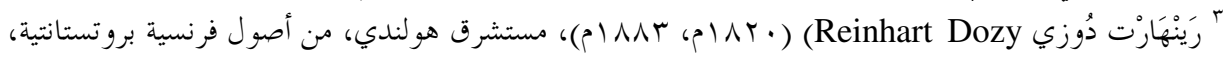

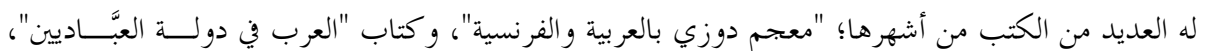

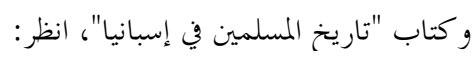

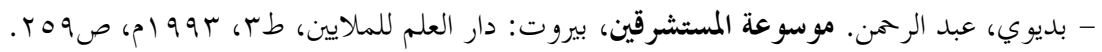

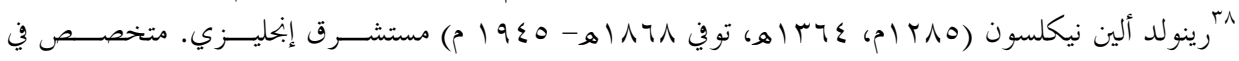

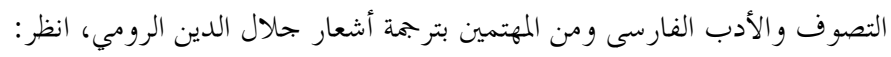

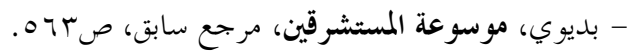

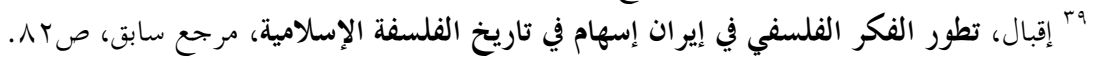




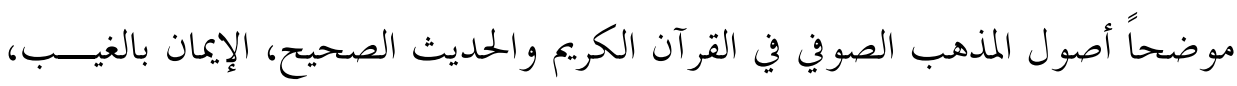

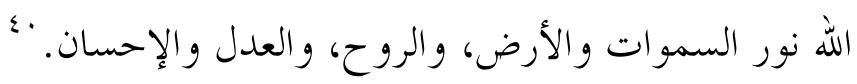

ث. نــزووع كثير من المسلمين نحو الغرب وانقسام العالم الإســلامي فكريــاً

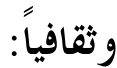

وهذا منطلق مهم في فلسفة إقبال المعرفية والفكرية في خطابه النقدي، فاحترامــه

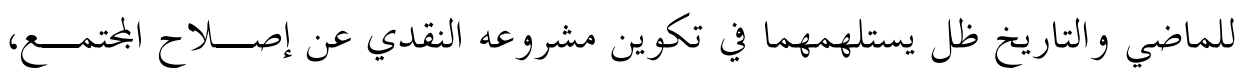

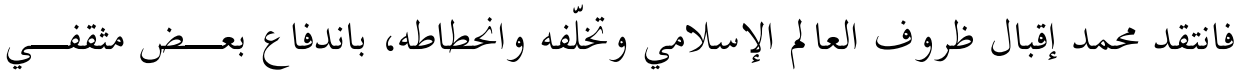

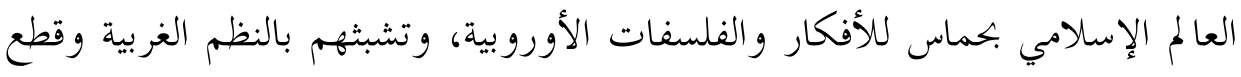

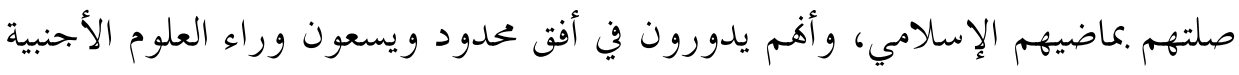

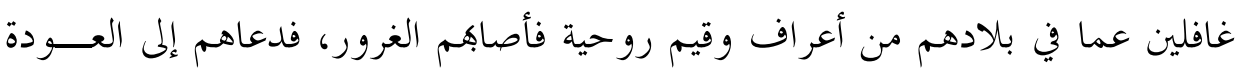

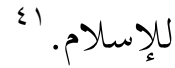

ومنطلق نقد إقبال للاتبحاهات الكبرى للفلاسفة الإســاميين، معرفتـهـ الواسـعة

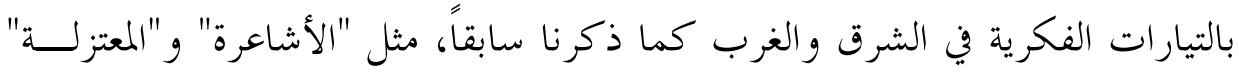

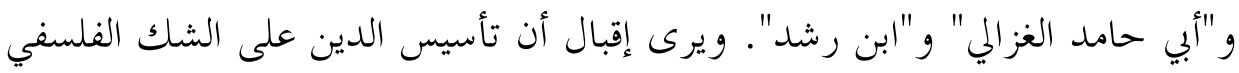

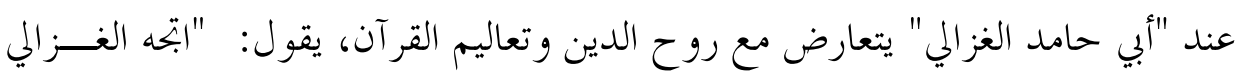

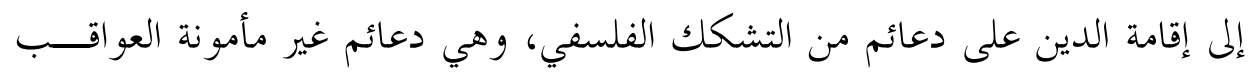

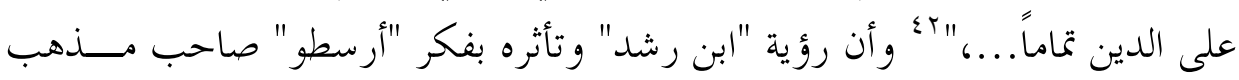
خلود العقل الفعّال، يتعارض مع نظرة القرآن إلى قيمة النفس الإنسانية وإلى مصيرها،

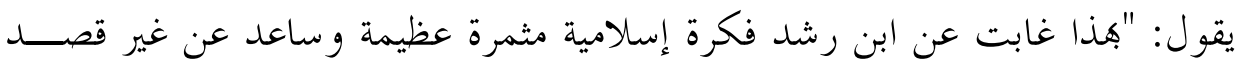
على نمو فلسفة للحياة تورث الضعف، وتغشى على بصر الإنسان عند نظره إلى نفسه

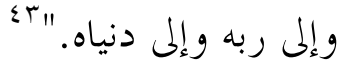

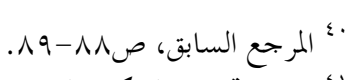

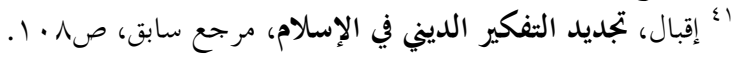

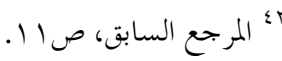

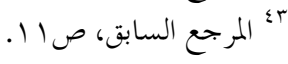


و اشتغال إقبال بالسياسة وتوثيق صلته بأحداث البحتمع الهندي، ثم انتخابه عضـــوا

بالملس التشريعي في البنجاب، ساعد على تحديد النقطة المحورية في تصور إقبال للعالم ولإسلام؛ إذ نادى بضرورة انفصال المسلمين عن الهندوس وتأسيس دولة إســلامية، نتيجة نـززوع كثير من المسلمين نحو الغربك، فكان .مثابة إستراتيجية تقوم أساساً على

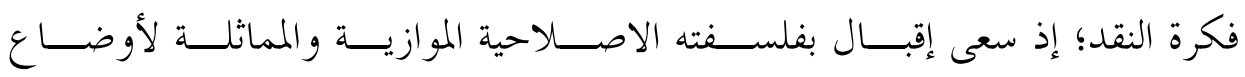
المسلمين، و العودة إلى النظم الإسالمية.

\section{ج. امتلاك إقبال البعد الروحي والعرفاي:}

الجانب الروحي في فكر إقبال له تأثيره في كتاباته؛ إذ تميّز خطابه النقدي بطـابع روحي، صار له هدف وغاية و مضمون، و المقصود به ترقية البحتمع روحياً، و الالتــزام بالتربية الروحية كما أمر بها الإسلام، و الارتباط الوثيق بالله سبحانه وتعالى، و انشداده

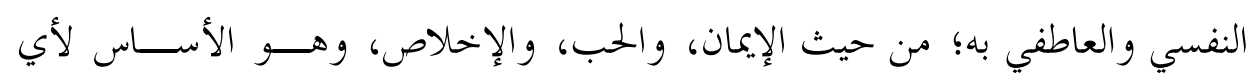
شخصية إنسانية قال رحمه الله: "إنّ الإنسانية تحتاج اليوم إلى ثلاثة أمور: تأويل الكون

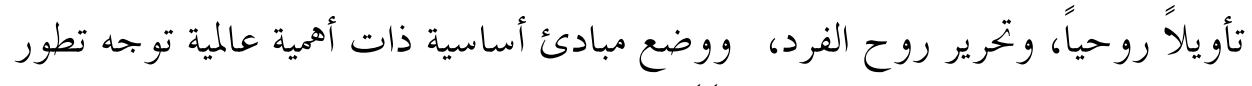

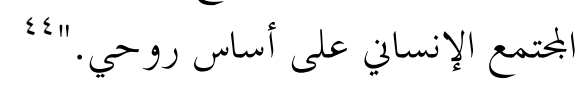

و يرى إقبال في القرآن المنهج الأمثل ليوقظ في النفس شعوراً أسمى، بين الخـــالق و المخلوق؛ لأن الواقع قد عرف صر اعاً متبادلاً بين الدين والحضارة، لهذا ثمة حاجة إلى استقرار الحياة الروحية، التي يمكن السمو بها عن طريت بتحي عالم جديد في النفس وهو ما يقرّه الإسلام، و لا يعرف تعارضاً بين المثال والواقع كما هو الحال في النصر انية؛ لأن

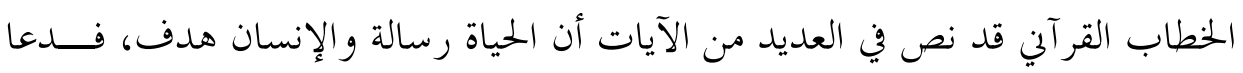
إلى التأمل في الطبيعة وبتجربتها.

و برز اهتمام إقبال بالتصوف والأفكار الصوفية، فالتجربة الصوفية لديه بتربة الأنا

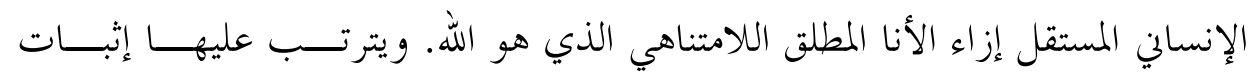

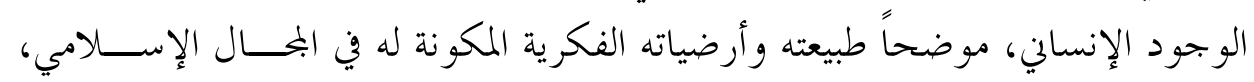




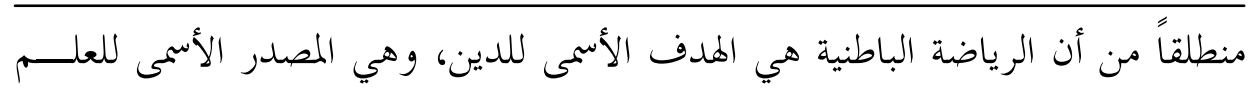
الإلهي وهو أسبق من ضروب التجارب الإنسانية، والقلب نوع من علم الباطن، وهذا لنّا

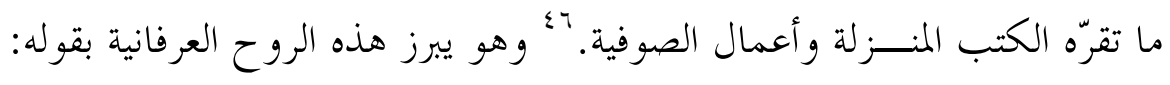
"انشد العون من شهود ثلاثة لتتحرى حقيقة مقامك

$$
\begin{aligned}
& \text { أو لها عرفانك لذاتك } \\
& \text { فانظر نفسك في نورك أنت } \\
& \text { و الثاني معرفة ذات أخرى } \\
& \text { فانظر نفسك في نور ذات سواك } \\
& \text { و الثالث المعرفة الإلهية } \\
& \text { فانظر نفسك في نور الله } \\
& \text { فإذا كنت ثابت الروع في حضرة نوره }
\end{aligned}
$$

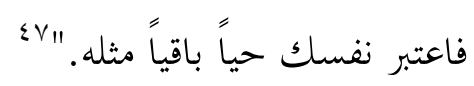

و يقف إقبال موقف الناقد من بتحارب الصوفية بملاحظاته النقدية التي أبداها علــى

التجربة الصوفية، بوصفها بتربة نفسية مباشرة، مثلها مثل التجارب الإنسانية، فهـي مئي

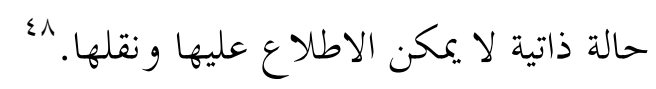

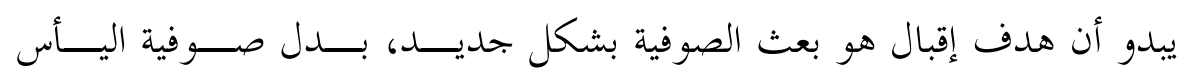

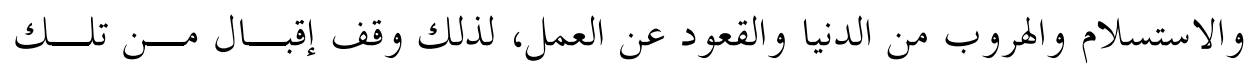

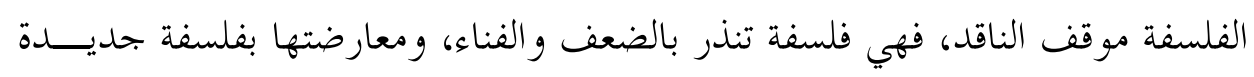

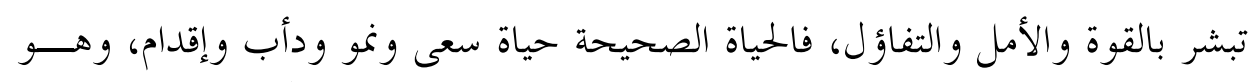

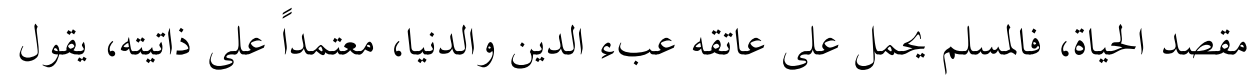
إقبال:

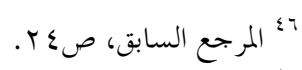

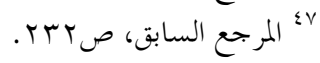

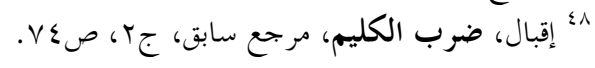




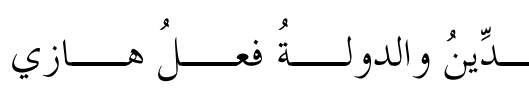

إلا كِلِ

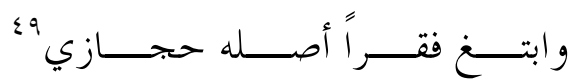

عبَّ علــى المـــؤْنِ ذي الليـــالي

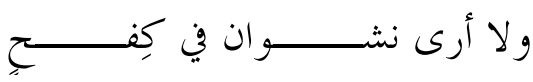

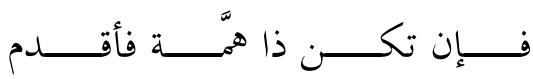

و مما ترتب على هذه الدراسة المنطلقات المعرفية و الفكرية و الفلســفية للخططـاب

النقدي عند إقبال، المتميزة بطابعها النقدي وبالتحليل المنطقي الرزين؛ إذ ساهم بشكل

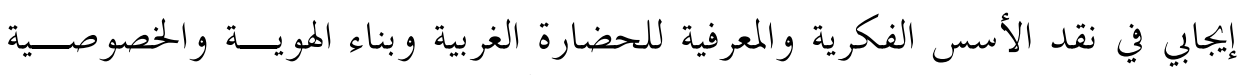

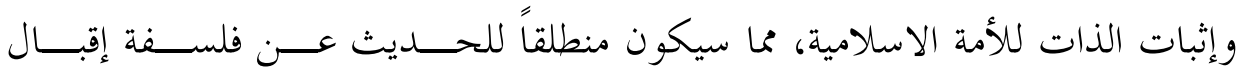
الاصلاحية في هدف الخطاب النقدي وأفقه.

ثانياً: هدف الخطاب النقدي وأفقه عند إقبال ودوره في بناء الثخصية الإســالامية المعاصرة لا شكَّ في أنّ عناو ين محمد إقبال تفصح عن ثابت منهججي يقوم عليه مشــروعه

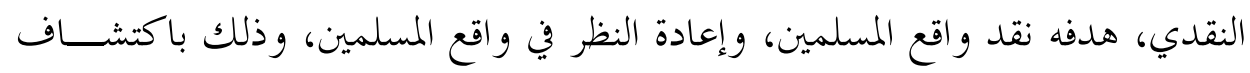
العناصر الأساسية للدين.

\section{1 إقبال النقدي:}

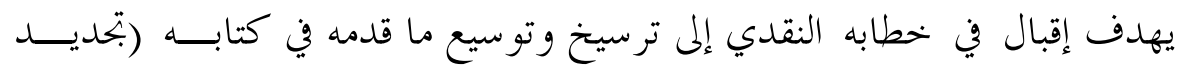

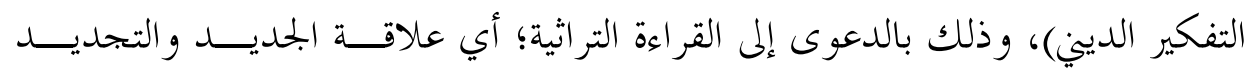

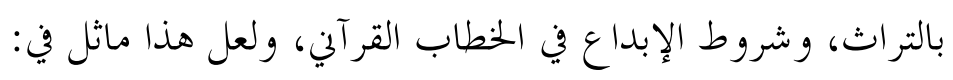
أ. تفكيك بنية الخطاب الذي يقوم عليه الفكر الإسلامي:

السؤ ال الذي استفز إقبال كثيراً، هو تخوفه من مبدأ الحر كة في بناء نظام الإســلام

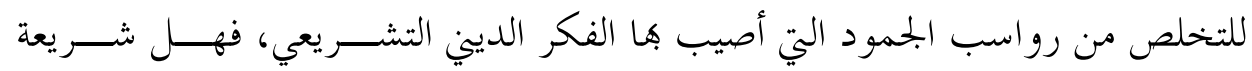
الإسلام قابلة للتطور؟ تصن 
هنا ينتقد إقبال منهج القدماء المتقدمين من فقهاء الإسلام في طريقة تعاملهم مـــع

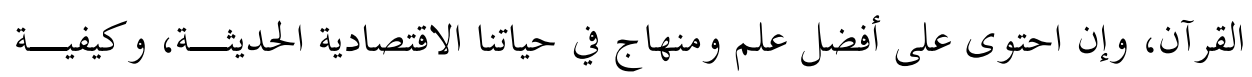
الاستفادة من تفسير الرسول تأويلاً جيداً. وينتقد إقبال الخلاف والجالحدل حول فكرة الإجماع في صدر الإسلام الذي تحول إلى نظام تشريعي ثابت و كذا القياس، وانتقد التفكير الإسلامي الذي ابته ابحاهاً

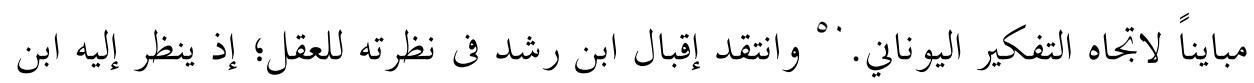

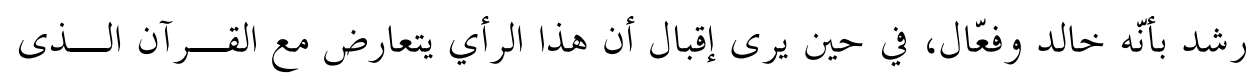

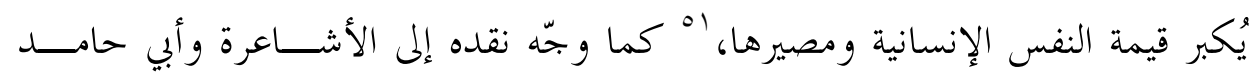
الغزالي وغيرهم، و المعتزلة في إدراك حقيقة الدين، به كاشفاً مدى الاستفادة من النتائج

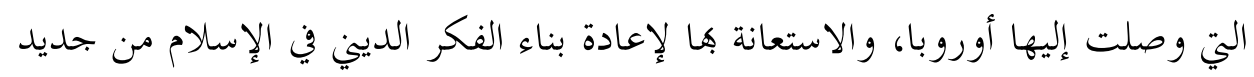
إذا لزم الأمر، يقول: "وهذا لا بدّ أن يصاحب يقظة الإسلام تمحيص بروح مســتقلة

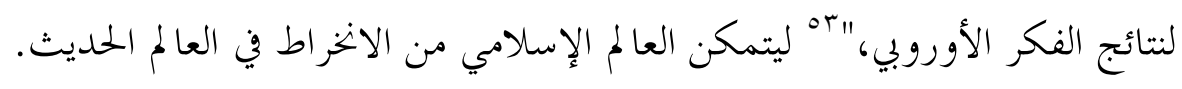
وذلك ليثبت إقبال من وجهة نظره قابلية الشريعة الإســلامية للتطـــور، يقــــل

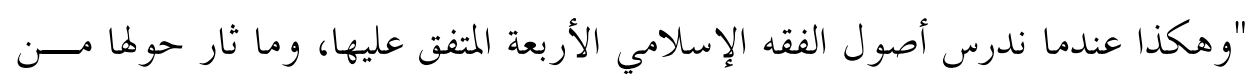

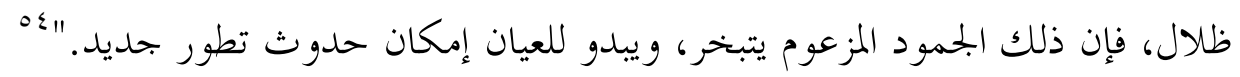
لقد كان أسلوب إقبال النقدي .مثابة ردِّ فعل لما لاحظه وأدركه في الأمة الإسلامية

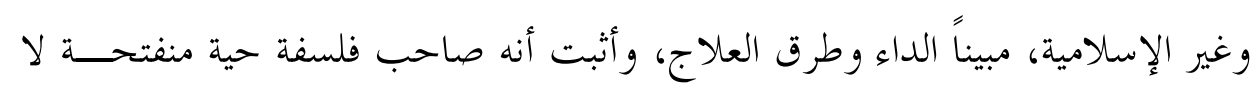

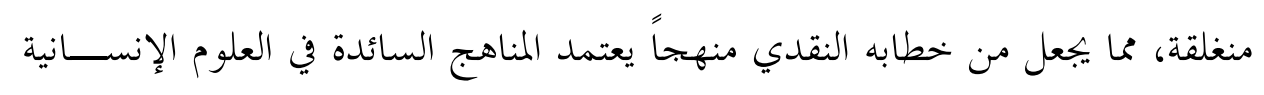
وفلسفاتا، وأنه خيار لا مفرّ منه.

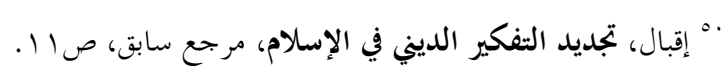

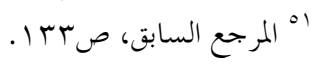

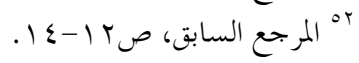

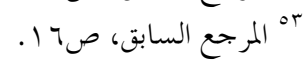

$$
\begin{aligned}
& \text { ؛ المرجع السابق، صرابق ص190. }
\end{aligned}
$$




\section{ب. بناء منظومة معر فية وشبكة مفاهمية:}

يعدّ إقبال من المتفردين السابقين إلى فحص مشروعات قراءة التراث الإســلامي

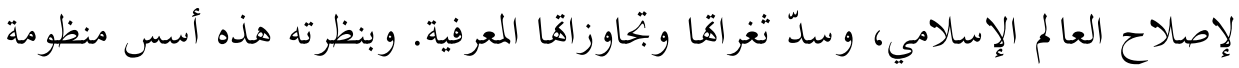
معرفية وشبكة مفاهمية، ساهم عن طريقها في إنتاج خطاب نقدي في إطار رؤية معرفية

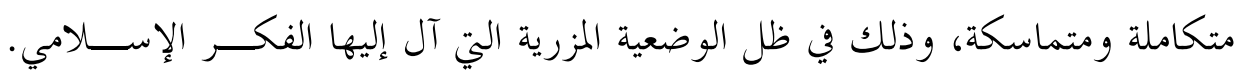

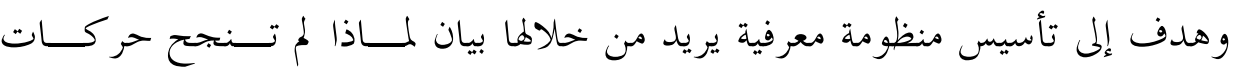

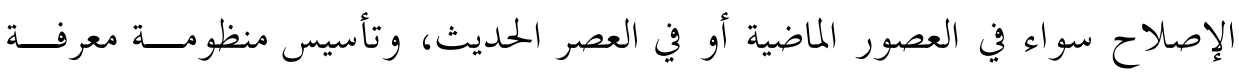

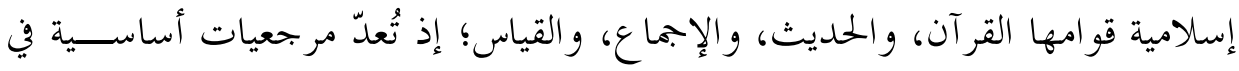
بناء منظومة معرفية إسلامية، وبناء منظومة قيم الحضارية الإسلامية، وذلك بناء القاء منهج

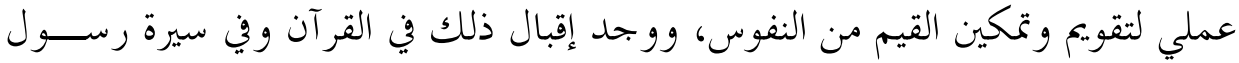

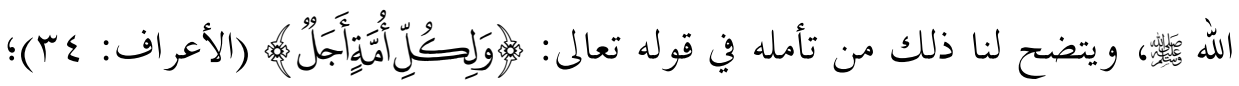

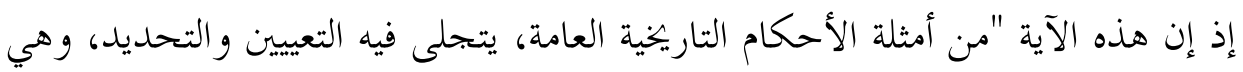

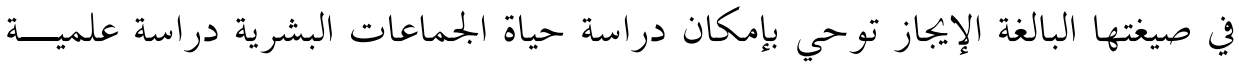

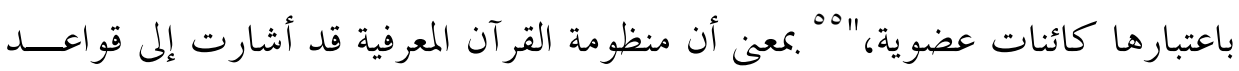

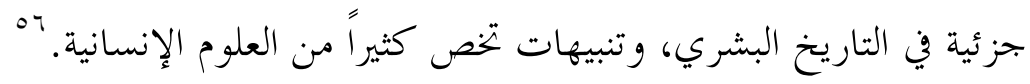

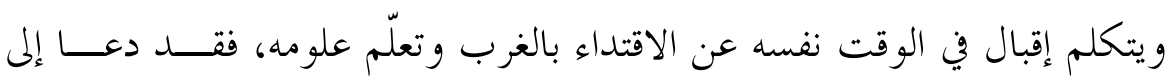

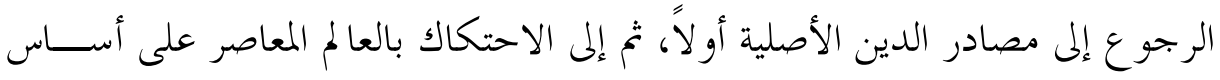

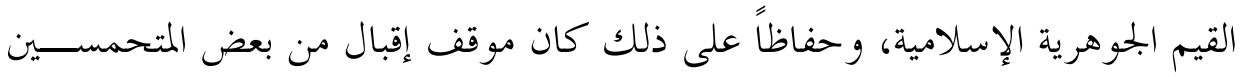

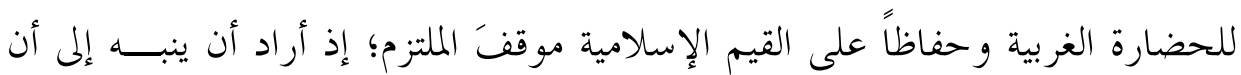

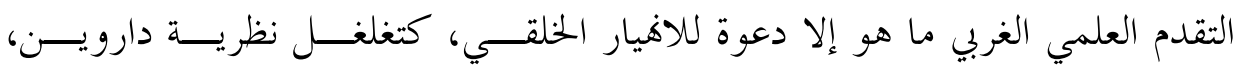

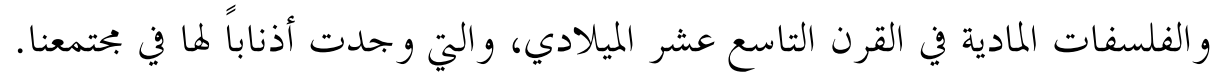

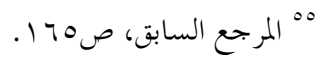

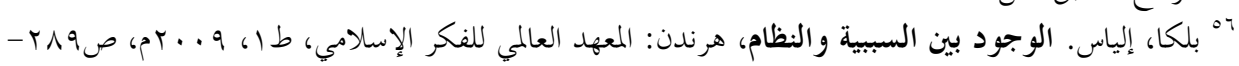




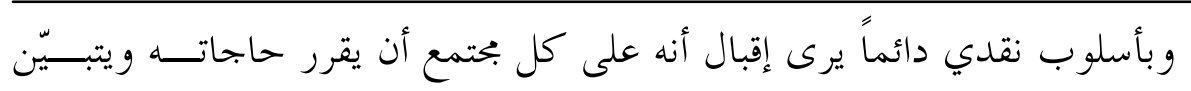

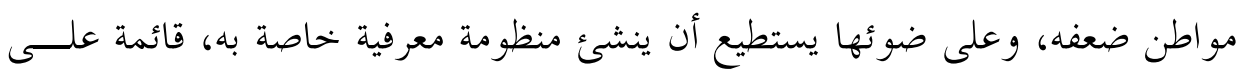

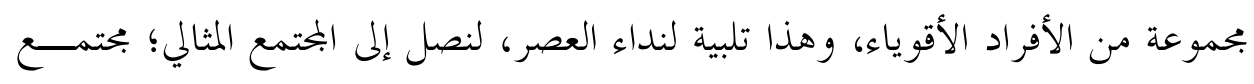

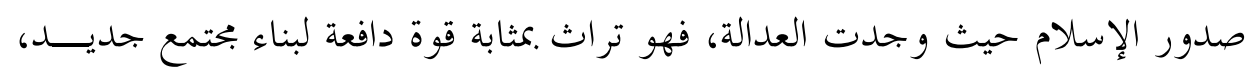

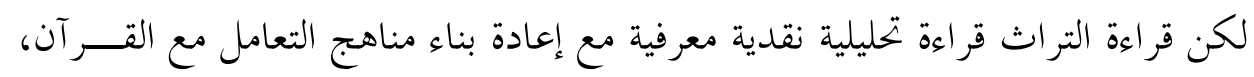

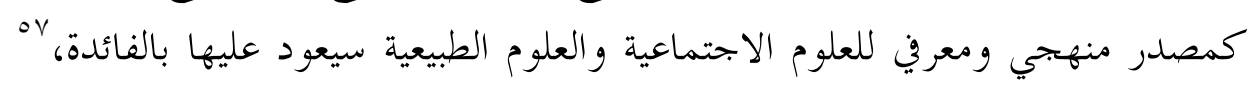

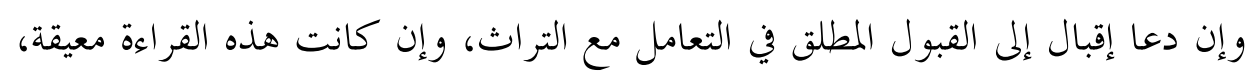

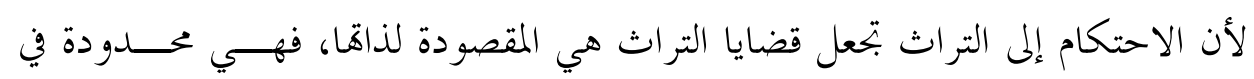
الزمان و المكان الذي وجدام الإت فيه.

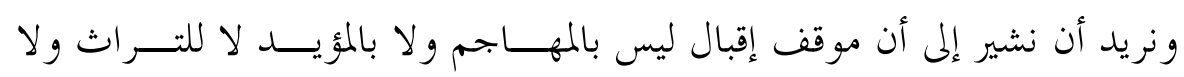

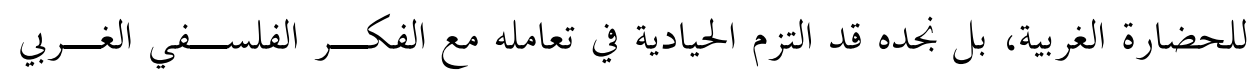

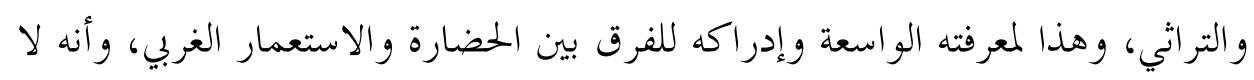

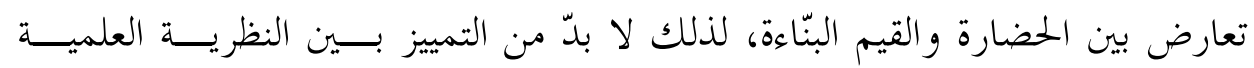

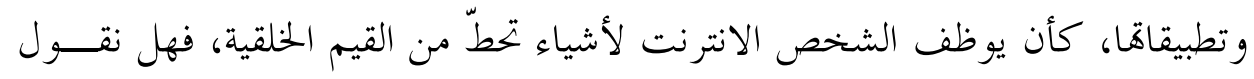

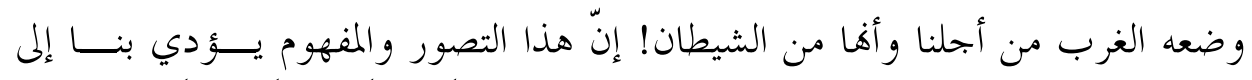

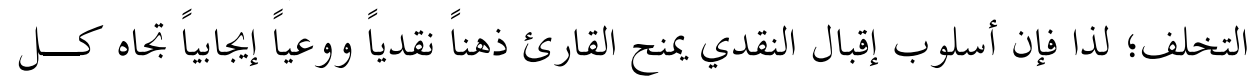
ما ينتجه من معرفة وعلم.

\section{Y. أفق الخطاب النقدي عند إقبال ودوره في بنـــاء الشخصــية الإســلامية}

المعاصرة:

حاول إقبال تشخيص الأزمة التي تعاني منها الأمة الإسلامية، وإن استقرّ في بيئسـة

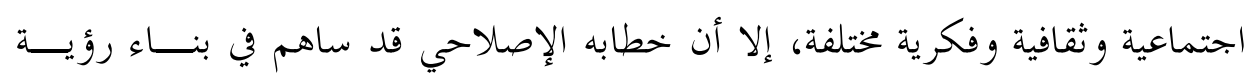

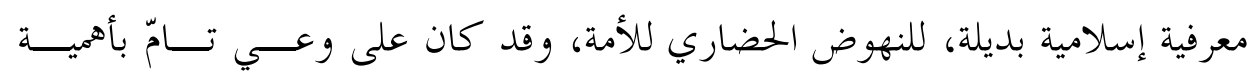

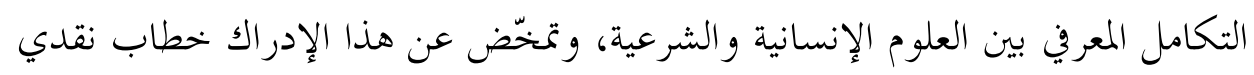

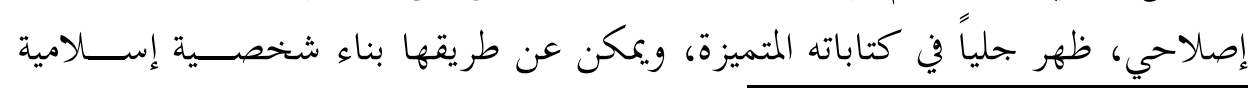

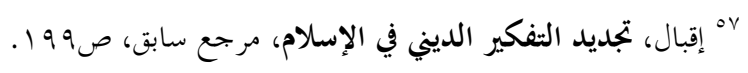


أفق الخطاب النقدي ومنطلقاته المعرفية والفكرية والفلسفية في مشروع إقبال الحضاري ع 19 فاعلة قادرة على الأداء الحضاري الإسلامي، كمفهوم الدين والإيمان عند إقبال، ودور

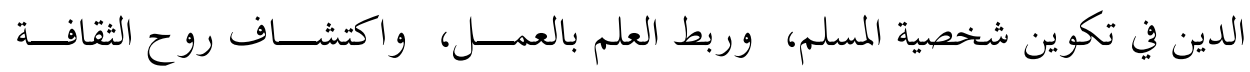

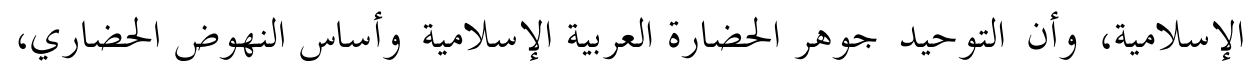

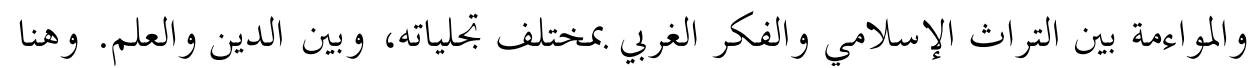

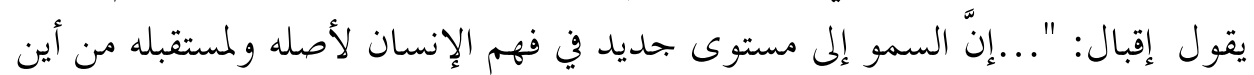

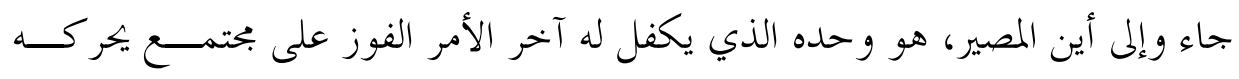

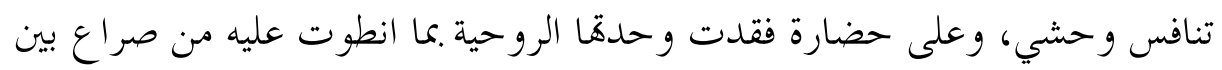

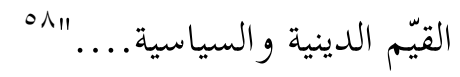

ومنهج إقبال الإصلاحي إعادة بناء الذات والفكر وإنشاء بحتمع فاضل، انطلاقـاً

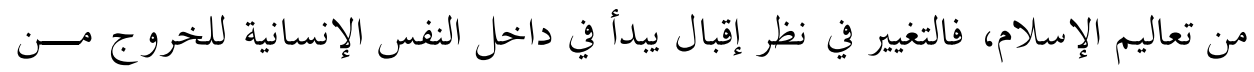

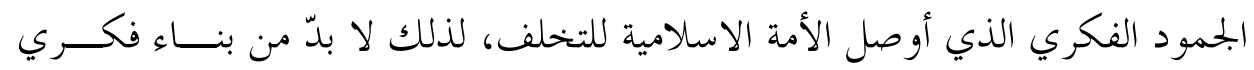
ليخر ج الفكر الإسلامي من أزمته، وبناء اجتماعي وسياسي لانعتاق الأمة الإســامية بلاءمية

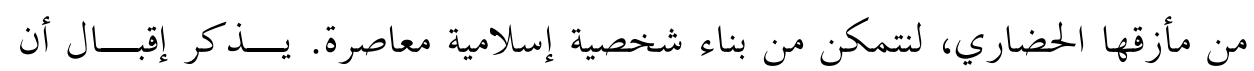

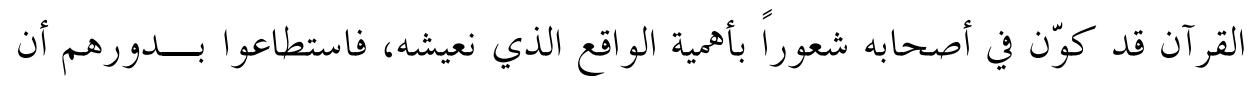

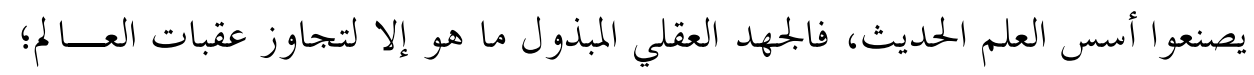

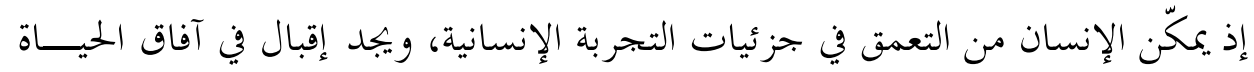

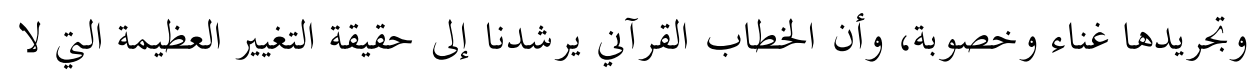

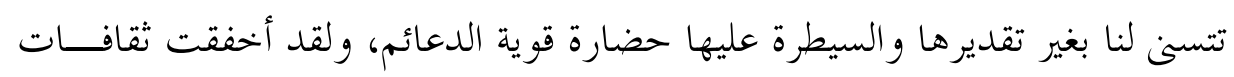

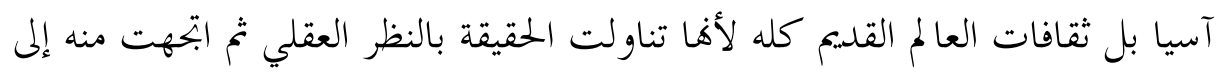

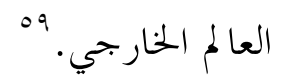

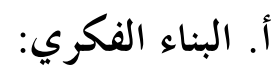

البناء يراد به التخطيط و التصميم و التنظيم، و الفكر هو العطاء المعنوي العقلي لأيّة

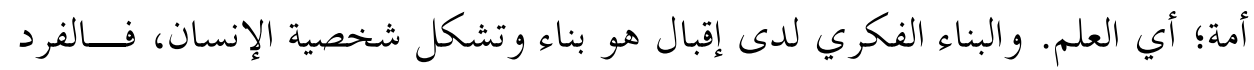

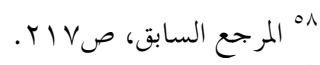

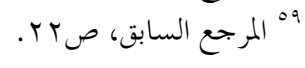


بحاجة إلى حركة وتغيير ونمو، وتنمية قدرات الفرد الفكرية والعقلية، لتكييف حياتسـه

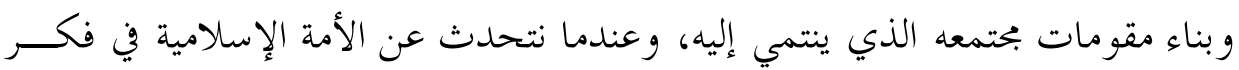
إقبال الإصلاحي، نفهم من كلامه أن الأمة الإسلامية الواحدة تتوحس حلد في عقيدها؛ أي

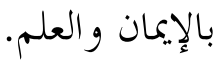

و.بما أن الارتقاء البشري ظاهرة مقتصرة على الإنسان لانفـــــاده هـــــه القـــوة

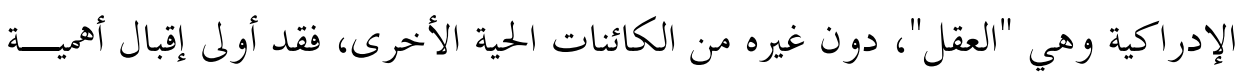

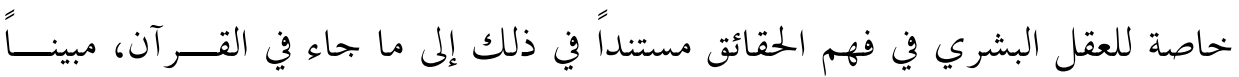

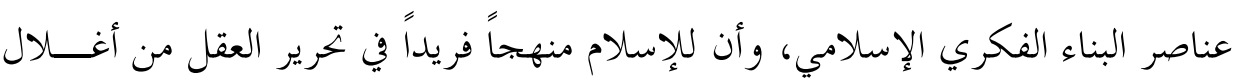
التحجر، فصحة العقائد ومعرفة الحق لا تتحقق إلا بحرية الفكر واستقلال الإرادة.

و يلفت إقبال النظّر إلى أن العقل ضوء ومصدره العلم، وأن الحقائق لا يـــدركها

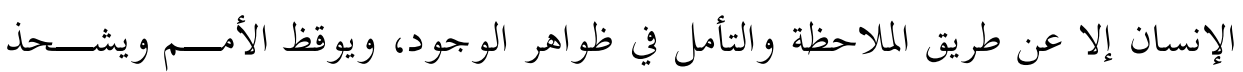
عزائمها، يقول:

ما ابن سينا كُحلت و الــــرازي"

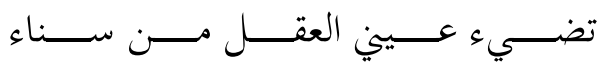

وإقبال في متابعاته النقدية وفي بناء فلسفة إسلامية جديدة، يرى أنّ حلّ مشكلات

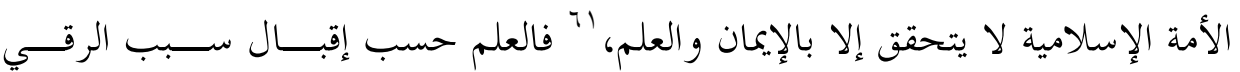

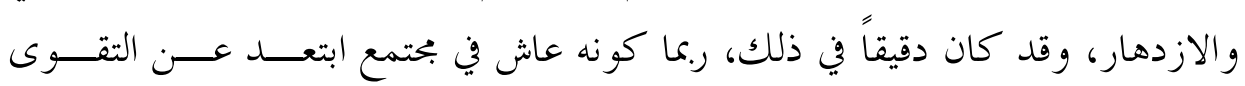
و الإيمان فتحول العلم إلى آلة للهدم يذكر قائلا:

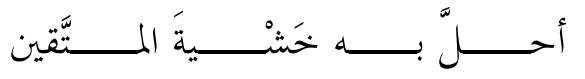

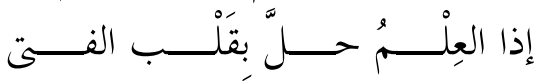

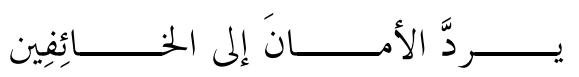

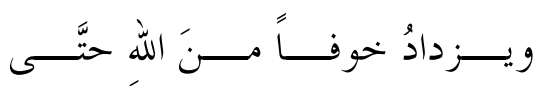

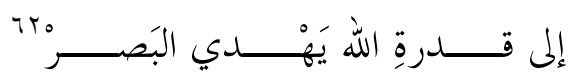

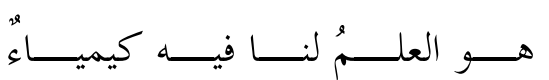

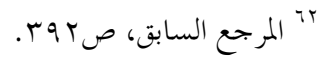


وهنا تتضح ملامح إقبال النقدية في فتح المدارك في مسار الإصــلاح و التجديــــ،

لذلك حثّ على إعمال العقل، فهو طريق للنقد الذاتي، وبه يمكن إدراك العالم، يقول:

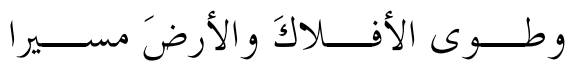

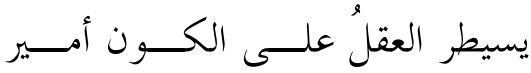

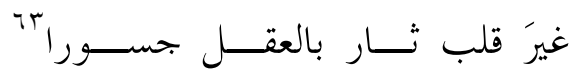

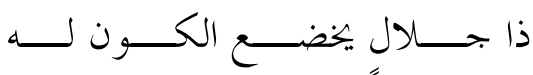
و.مما أن العقل والقلب هما سلاح الذات في نظر إقبال، كون القلب قـــوة خارقـــة لاكتشاف الحقائق، فهو يفقه الأمور عن طريق العلم، ويبرز ذلك عند إقبال في مــــى

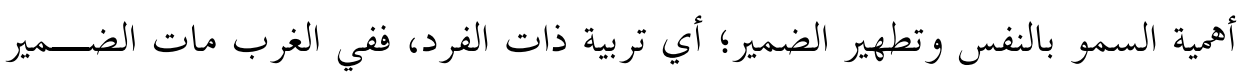
و في العالم العربي ماتت الذوات. و الإنسان في نظر إقبال أشرف المخلوقات، فالكائنات

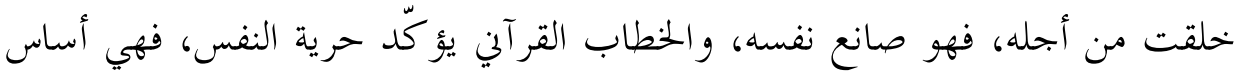
شخصية الفرد، وحين يعرف الإنسان قدرته في السيطرة على العالم، تتولد لديه رغبـــة في تربية الذات ليصل للمطلوب، يقول إقبال: "...وبعد فإن العقل لا يمكن أن يتصوَّر

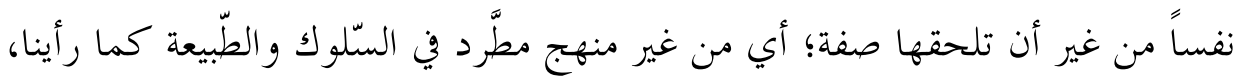

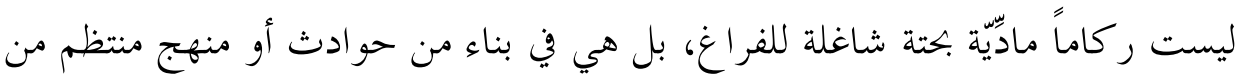

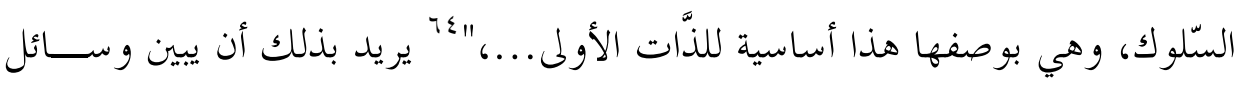
الدفاع الذاتية ضد الإحباط الذي سيؤدي إلى الإصابة بالأمراض النفسية؛ لنبي أنفسنا

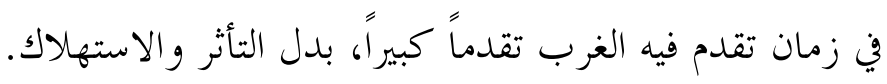

ودرس إقبال أوضاع المسلمين دراسة عميقة فاحصة، فدعاهم إلى التخلص مــن عقدة النقص أمام الغرب، كاشفاً النقاب عن حقيقة الحضارة الغربية لتخليص المسلمين مما أصاهم من تقليد غيرهم، سببه الجمود الفكري الذي أصاهم، ما جعلهم يعيشــون

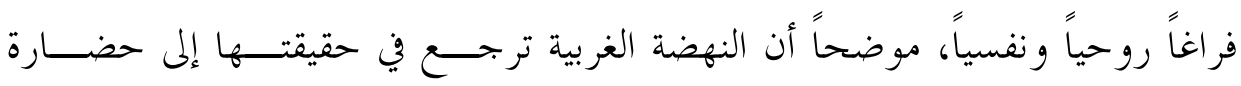
المسلمين، وأنه لا سبيل للخلاص من ذلك إلا بالرجوع إلى الإسلام، جّ ولا يمنع الفرد

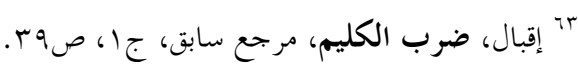

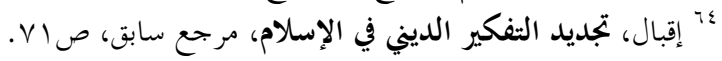

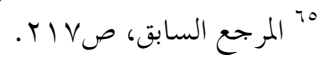




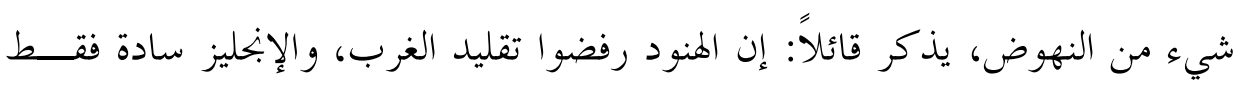
على جسد المسلم لا على قلبه. ويكون إقبال بذلك قد قام ببناء رؤية صحيحة، تمكّــن الشخصــية المســلمة في

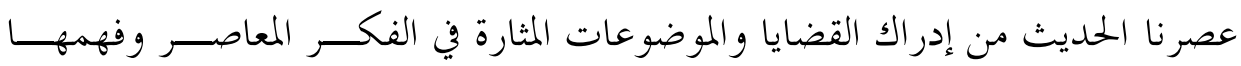
بصورة واضحة و متكاملة ومنسجمة.

\section{ب. البناء الاجتماعي والسياسي:}

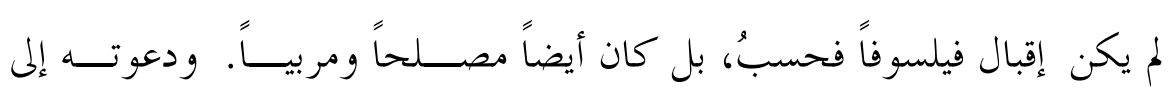
الإصلاح الفكري والاجتماعي ركّز فيها على بناء الذات، التي تعدّ من الدعوات الــيتي

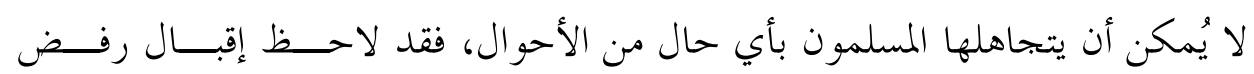

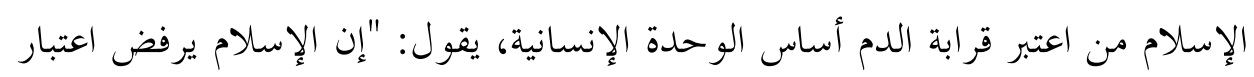

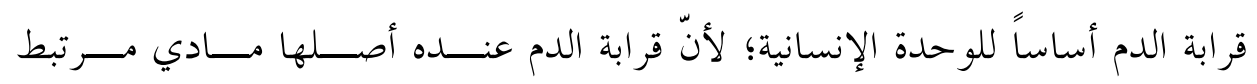

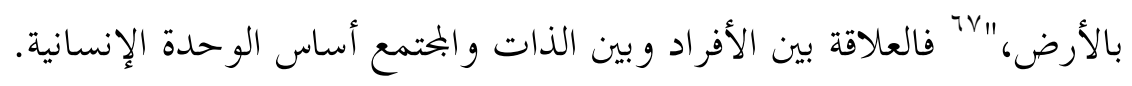

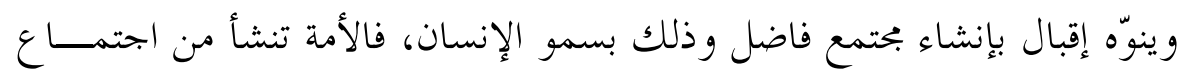

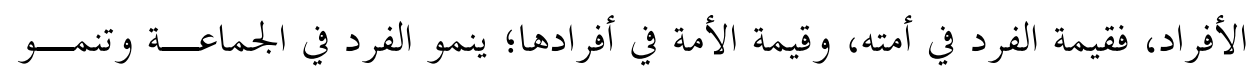
الجماعة عن طريق الأفراد، يقول:

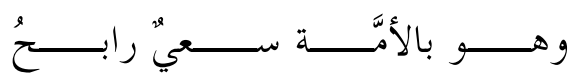

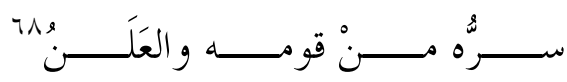

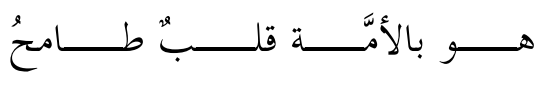

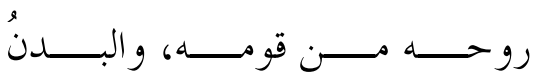

و بناء على ذلك يريد إقبال تعريف المســـلمين بأنفســـهم و بأهــــــافهم الذاتيــة،

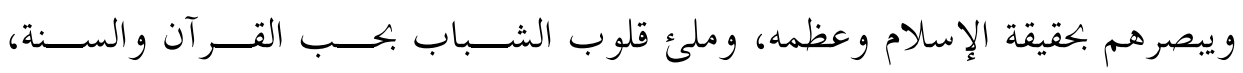

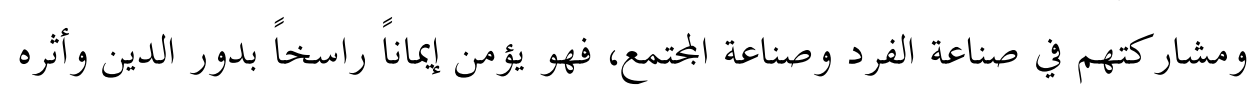

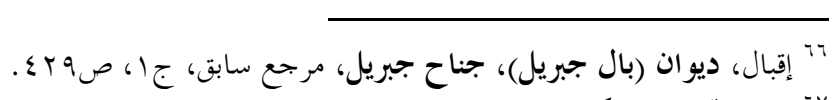

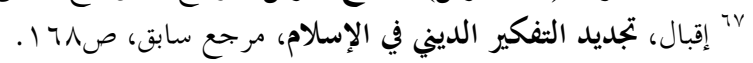

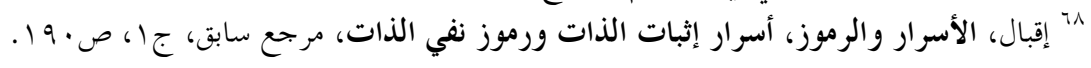




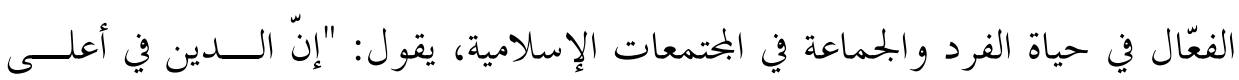

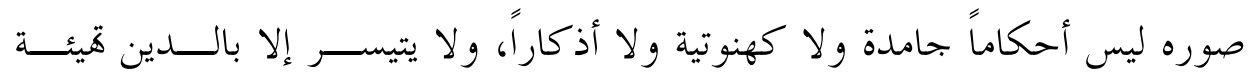

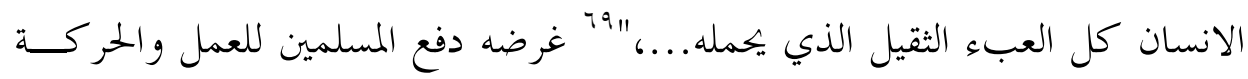

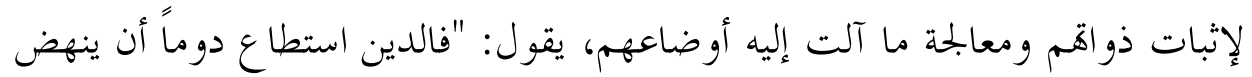

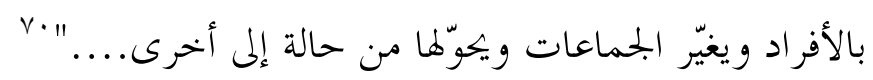
يشير إقبال هذذا إلى أنّ الفرد لا تكتمل حياته إلا في ظل الجماعة، ونشر التـــوازن بين أفراد المحتمع الواحد، ونشر الحرية والمساواة بين بني آدم. وبنحه يقيم مقارنة بـسين

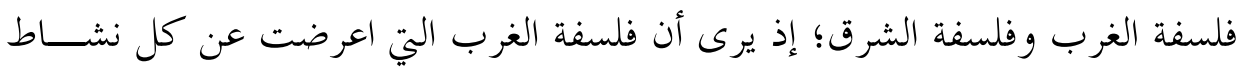
روحي قد انحازت كلياً إلى العقل، أما فلسفة الشرق؛ فيرى إقبال أها على العكس من إنى

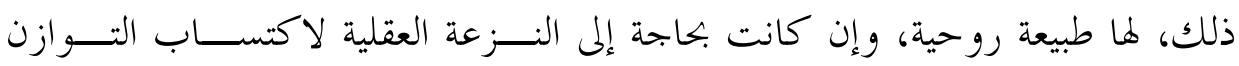
أيضاً.

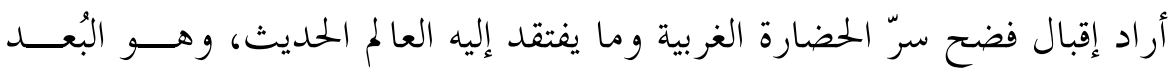
الروحي الذي منبعه الدين، الذي يُكسب الإنسان قوة ويبين مستقبله ويحدد مصـسيره،

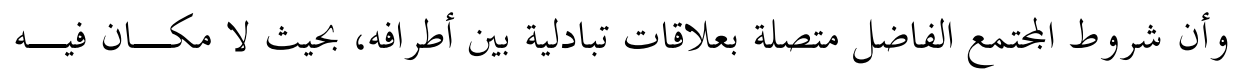
للتقوقع والانعز ال و الاغتراب و الانطواء على الذات.

\section{خاتمة:}

إنّ سبر أغوار فكر محمد إقبال في كتاباته ومؤلفاته لا يخلو مـــن متعــة، فهــــهـ

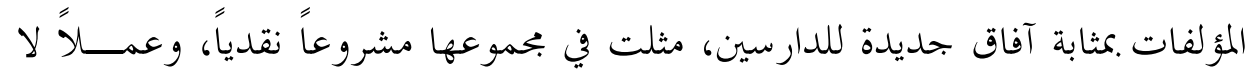

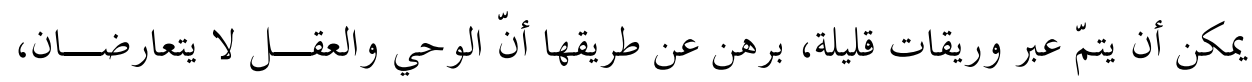

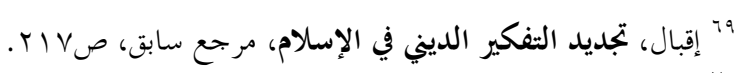

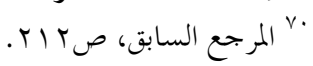

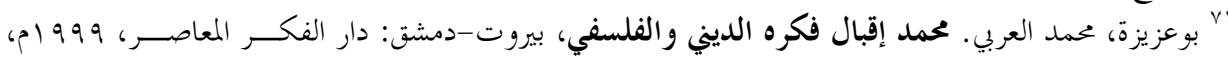


محاولاً النهوض بالعقل المسلم وبحديده، ووضع خطة تقود الأمة الاسلامية إلى المقدمة، و بناء فلسفة دينية بناء جديداً.

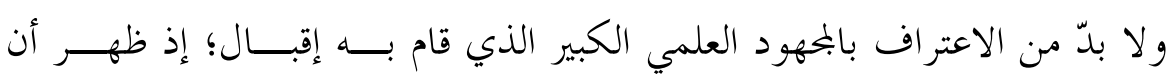

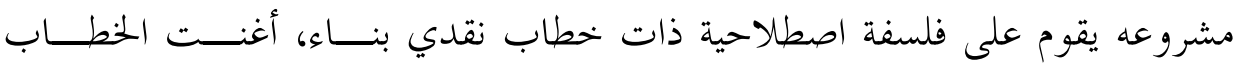
الإسلامي نظرياً ومفهومياً ومنهجياً.

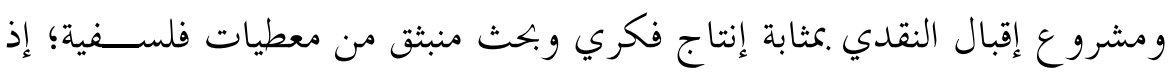

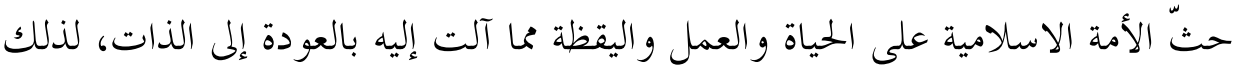

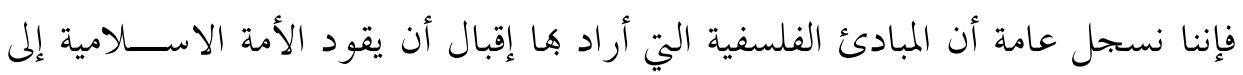

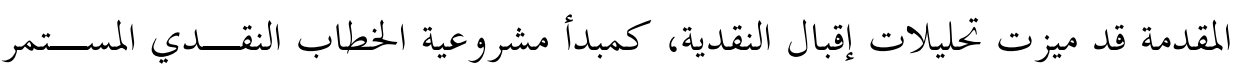

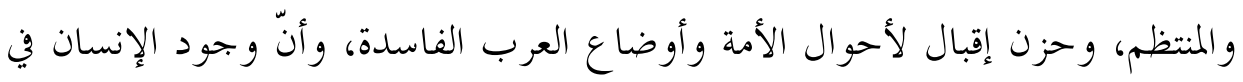

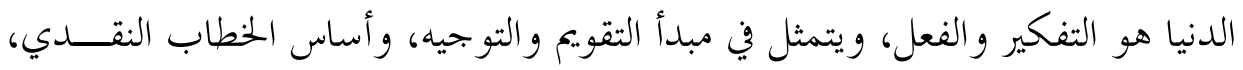
و مبدأ إممان إقبال بحرية الفكر و التأويل.

كشف لنا الخطاب الإقبالي عن البعد المعرفي والفلسفي لفكر إقبال، المتميز بالطابع

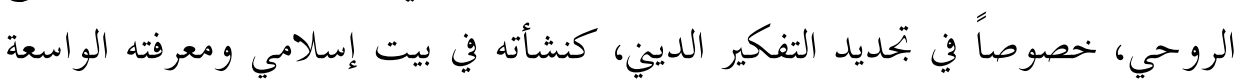

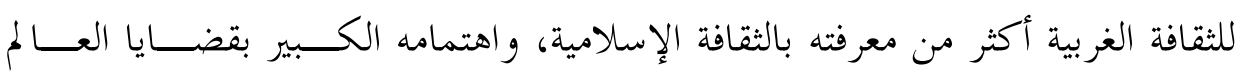

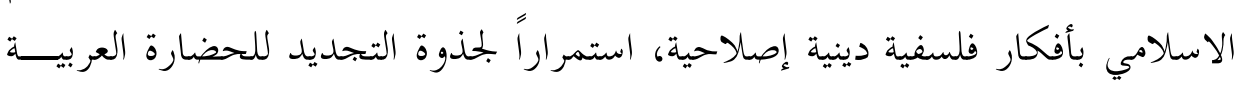
الإسلامية، وفق تصور إنساني في ضوء التجربة الصوفية الروحية، وبناء رؤية صحيحة

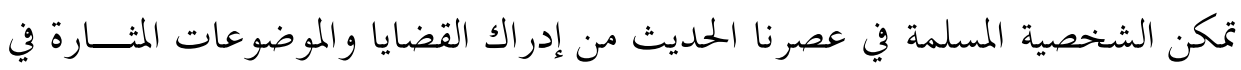
الفكر المعاصر وفهمها بصورة واضحة ومتكاملة ومنسجمة. 